\title{
LAS CAJAS DE AHORROS ESPAÑOLAS EN EL SIGLO XIX: ENTRE LA BENEFICENCIA Y LA INTEGRACIÓN EN EL SISTEMA FINANCIERO *
}

\author{
ÁNGEL PASCUAL MARTÍNEZ SOTO \\ Universidad de Murcia
}

\section{RESUMEN}

En el trabajo se aborda el proceso de creación y desarrollo de las cajas de ahorro y montes de piedad a lo largo del siglo xix, coincidiendo con los cambios que implicó la implantación de las normativas e instituciones del liberalismo económico en nuestro país. Para ello se estudia la doble función benéfico-financiera que cumplieron a través de la captación de depósitos de ahorro provenientes, sobre todo, de las capas populares urbanas y de la pequeña burguesía, para transmitirlos en forma de préstamos de diversa consideración y pequeño volumen a las clases populares a través de los montes de piedad, $\mathrm{y}$ de alcance mucho mayor a industriales y comerciantes. También se trata de evaluar el peso real de las operaciones de este tipo de entidades dentro del sistema financiero español del siglo $\mathrm{xxx}$.

\section{ABSTRACT}

This work tackles the creative process and the development of the savings banks and trust companies throughout the $19^{\text {th }}$ century, coinciding with the changes that implied the introduction of the regulations and the institutions of economic liberalism in Spain. We study the double charitable financial functions which was fulfilled by gaining control over the savings deposits. Those deposits come mainly from the low income urban groups, and later transferred in the turn of loans to small borrowers in industry and commerce.

* El presente trabajo se ha beneficiado de los comentarios, sugerencias y críticas de las profesoras María Teresa Pérez Picazo y María Asunción Albentosa. También quiero mostrar mi agradecimiento a los evaluadores anónimos que se tomaron el trabajo de leerlo y criticarlo con detenimiento para sugerir aspectos que han contribuido a mejorar la redacción original. 


\section{INTRODUCCIÓN}

El binomio formado por los montes de piedad y las cajas de ahorros a lo largo del siglo XIX dio a estas últimas la imagen de entidades con un marcado carácter de beneficencia, siendo excluidas de los circuitos financieros por los analistas e historiadores de la economía hasta tiempos recientes. Los estudios de un reducido grupo de estos últimos, G. Tortella (1974), J. Nadal y C. Sudriá (1983) y M. Titos (1978, 1989, 1991, 1993 y 1997), entre otros, han servido para rescatar del olvido a dichas instituciones sustrayéndolas al mismo tiempo de los estudios del tipo de «crónica amable y empalagosa, una muestra de la peor bussines bistory» ${ }^{1}$.

El desarrollo conseguido por las mismas durante la precitada centuria y el alcance de su labor desde la doble perspectiva benéfica y financiera justifica que se siga investigando con el fin de mejorar nuestro conocimiento sobre el papel que desempeñaron en el modesto crecimiento habido en España durante la segunda mitad del Ochocientos. Parece claro que en principio, cuando se funda la primera caja en 1838, no tenía finalidad de lucro sino meramente filantrópica. Dimensión que iba a concretarse en una doble línea de iniciativas. Pedagógicas, primero, plasmadas en la difusión de hábitos previsores entre las clases populares de las ciudades. Y económicas, después, a través de la colocación de una parte de los excedentes financieros en el sostenimiento de obras sociales.

Para facilitar el análisis de las cajas he adoptado una división del período estudiado en dos etapas, una comprendida entre 1839-1868 y otra entre 1869-1904. La primera se caracteriza por ser el inicio de la implantación de este tipo de entidades, el cual estuvo marcado por las ideas de las autoridades liberales en lo relativo a fomentar la iniciativa privada filantrópica de la burguesía urbana, de manera que ésta aportara los depósitos iniciales (siempre remunerados) y los cuadros necesarios para la dirección de las instituciones; durante estos años se emitirá el Real Decreto de 29 de junio de 1853 que fue la primera norma reguladora con carácter global, al tiempo que se producían las primeras fundaciones ( 18 cajas y 12 montes de piedad). El funcionamiento de las cajas tuvo serias restricciones operativas producto de la aplicación de esta normativa legal, debido a su consideración como entidades de beneficencia, lo que incluía la prohibición a los montes de intervenir en operaciones de crédito destinadas a negocios u operaciones mercantiles. A pesar de estas limitaciones los grupos fun-

\footnotetext{
' Cita tomada de la introducción del trabajo de J. Nadal y C. Sudriá (1983), p. 1.
} 
dadores operaron con un alto grado de autonomía debido a la escasa capacidad de control por parte del Estado.

La segunda etapa (1869-1904) fue la del crecimiento atomizado y la consolidación de las entidades dentro del sector financiero. El crecimiento de los recursos ajenos captados llegará a desbordar las necesidades de liquidez de los montes, lo que hizo necesario la diversificación de los tipos de operaciones de crédito que realizaban, apareciendo de esta manera los préstamos personales con fiadores, los hipotecarios sobre fincas, la creación de carteras de valores, la adquisición de inmuebles, etc. De esta manera se continuó rebasando los límites establecidos por la normativa oficial, lo que obligó al Estado a una regulación que se produjo a través de la Ley de 29 de junio de 1880 que posibilitó la creación de la mayor parte de las cajas existentes en la actualidad. El papel de los montes se fue debilitando al no poder absorber con sus operaciones los recursos ajenos de las cajas, lo que dio mayor libertad de acción a éstas.

A lo largo de la comunicación iremos detallando aspectos relacionados con la función financiera de los indicados establecimientos, especializados en lo que J. Revell denominó «estrategia de banca al por menor» ${ }^{2}$, analizando la captación de depósitos por medio de imposiciones en el período 1839-1904, al tiempo que se tratará de elaborar el perfil socioprofesional de su clientela. Con el fin de contextualizar el funcionamiento de los mismos dentro del sistema financiero español, se comparará la evolución de los fondos captados con la descrita por la banca privada, tanto en conjunto como en sus diferentes subsectores. También he cotejado la evolución de dicha magnitud con las cifras del PIB, de la Renta Nacional y de los Presupuestos de ingresos del Estado durante el período, con el fin de tener una referencia respecto a las macromagnitudes indicadoras de la evolución económica.

Desde el punto de vista del análisis cuantitativo se han trazado las líneas generales de la distribución territorial de las imposiciones en el período 1875 a 1906, lo cual nos permite establecer cuáles fueron las cajas que presentaron mayor dinamismo, alcanzando la potencialidad suficiente para desarrollar las funciones que se les habían asignado. Asimismo se han calculado la dimensión media de las cuentas de ahorro - dato necesario para la caracterización social de la clientela-, el valor medio de los depósitos por habitante y el tanto por ciento de imponentes sobre el total de estos últimos. La comparación de las cifras obtenidas con las correspondientes a otros países del entorno nos ha ayudado a valorar el lugar que

\footnotetext{
${ }^{2}$ J. Revell (1989), pp. 36-45.
} 
ocupaban las cajas españolas en un contexto más amplio. Por último he reconstruido la serie de los préstamos realizados (número, capital y valor medio) por los montes de piedad que funcionaron entre 1862-1904, lo que puede arrojar luz sobre el destino que dieron las cajas a sus recursos, al esbozar la tasa de cobertura de los depósitos de las mismas respecto a los préstamos concedidos por los montes de piedad.

\section{EL ORIGEN DE LAS CAJAS DE AHORROS, 1839-1868: ENTRE LA FILANTROPÍA Y EL CONTROL SOCIAL}

La preocupación por la difusión del ahorro se remonta al siglo XVш, estando presente entre los ilustrados franceses, como así lo indica el artículo dedicado a la previsión y al ahorro en la Enciclopedia de Diderot y D'Álambert ${ }^{3}$, en el cual se recomendaba la propagación y apertura de entidades en las que pudieran depositar los recursos líquidos en pequeñas sumas los particulares, así como retirarlas con entera libertad. Otra influencia decisiva desde el plano teórico será la del filósofo utilitarista inglés J. Bentham ${ }^{4}$, quien señaló la necesidad de fundar los por él denominados Frugality Bank, para mejorar la situación de las clases populares, por medio del desarrollo de hábitos de ahorro, evitando con ello la intervención del Estado y de las instituciones religiosas de caridad.

Producto de esta línea de pensamiento será la fundación en Tottenham por iniciativa de Priscilla Wakelfield (1796) de una caja para los ahorros de niños pobres, la cual se transformó en 1804 en el primer saving bank inglés. Este modelo se difundiría rápidamente por toda Gran Bretaña; en $1810 \mathrm{H}$. Duncan fundaba en Ruthwwell (Escocia) otra caja, a la que siguieron las de Bristol (1812), Uckelfield y Croston (1814), Edimburg y Londres $(1816)^{5}$. Anteriormente se habían establecido en Alemania otras de parecidos objetivos denominadas versorgungsanstalt, la primera de las cuales inició su

${ }^{3}$ Sobre este aspecto ver el trabajo de Daniel Duet (1981), pp. 110-118.

${ }^{4}$ H. Oliver Horne (1947), pp. 27-29, mostró la relación directa entre las recomendaciones de los escritos de J. Bentham y la creación de Cajas de Ahorros en Gran Bretaña. $\mathrm{El}$ interés de los economistas clásicos por este tipo de instituciones estuvo determinado por su adhesión a la teoría malthusiana de la población con el consiguiente ataque a las leyes de beneficencia. Sobre este asunto consultar la correspondencia entre Ricardo y Trower en D. Ricardo (1959), Obras y correspondencia, México, FCE, pp. 24-25, 30, 48 y 165-166.

"El fundado en Londres recibió el nombre de City of London Saving Bank y entre sus directores encontramos figuras destacadas como Ricardo, Tower, Malthus, Hume o Torrens. 
andadura en Hamburgo en 1778, a la que siguieron las de Oldenburg (1786), Kiel (1796) y Gottiguen y Altona (1801), y desde allí se propagaron a Suiza.

En nuestro país será a partir de los últimos años de la década de 1830 cuando se inicie un movimiento en este sentido. Su introducción se originó debido a los contactos que los liberales españoles exiliados en Inglaterra durante la Década Ominosa tuvieron con los círculos utilitaristas ${ }^{6}$. Será durante el gobierno liberal del moderado Martínez de la Rosa cuando tenga lugar el inicio de las cajas de ahorros ( $\mathrm{RO}$ de 3 de abril de 1835); entre los primeros propagandistas encontramos a figuras ligadas a la Sociedad Económica Matritense como Quevedo San Cristóbal, Mesonero Romanos, F. Nard, S. Vela y J. Vizcaíno, Marqués de Pontejos ${ }^{7}$. El personaje central sería Mesonero Romanos, que desde la dirección del periódico Diario de Madrid promocionó la idea de fundar un establecimiento en la capital, lo que se logrará cuando el Marqués de Pontejos presente un proyecto al gobierno liberal y éste lo apruebe por Real Decreto de 25 de octubre de 1838 (Gaceta de 31 de octubre) en el que se ordenaba la creación de la Caja de Ahorros de Madrid en beneficio de las clases menos acomodadas. Al mismo tiempo se aprobaba un Reglamento de funcionamiento (Real Orden de 17 de julio de 1839) que establecía que la sede de la entidad estaría en el edificio del Monte de Piedad y que los capitales que ingresara la caja se colocarían en las operaciones de crédito del Monte.

El 1 de febrero de 1839 la Caja publicó y difundió una instrucción, obra de Mesonero Romanos ${ }^{8}$, en la que se glosaban las ventajas de tales instituciones para las clases menos favorecidas, sus tipos de operaciones y se avisaba de la apertura de las oficinas el 17 de ese mismo mes. Este documento contenía de manera simplificada buena parte de los presupuestos y concepciones que alimentaron ideológicamente a las cajas, que se presentan como instrumentos de regeneración moral y material de las

${ }^{6}$ Sobre esta influencia del utilitarismo inglés en los fundadores de las primeras cajas de ahorros españolas se han pronunciado autores como N. Pardo Pimentel (1869), B. Antón Ramírez (1876) y autores actuales como C. Ródenas (1978), J. Nadal y C. Sudriá (1982), P. Tedde de Lorca (1991) y M. Títos (1991).

${ }^{7}$ La primera publicación la realizó Mesoneros Romano en su trabajo Apéndice al Manual de Madrid que escribió en 1834, al cual siguió el de Sebastián Vela en 1835 para la Real Sociedad Económica Matritense y la Memoria sobre el modo de establecer y generalizar en España las Cajas de Aborros y Sociedades de Socorros Mutuos realizada por Francisco Quevedo San Cristóbal. Un artículo anónimo apareció en El Amigo del País en 1844 resaltando la necesidad de propagar este tipo de instituciones y en 1848 aparecía el libro Instrucción para el pueblo. Cien tratados sobre los conocimientos más útiles e indispensables de Francisco Nard, el cual dedicaba su tratado 95 a las cajas de ahorros.

${ }^{8}$ Así lo indica B. Antón Ramírez (1876), p. 170. 
clases populares ${ }^{9}$, al tiempo que constituyen un elemento de estabilización social al servicio del nuevo orden burgués ${ }^{10}$. La idea estaba presente en la Real Orden de 3 de abril de 1835, por la cual el gobierno liberal de Martínez de la Rosa daba su apoyo oficial a la creación de dichas entidades en España, pero con una orientación intervencionista consistente en la utilización por el Estado del ahorro popular para la financiación pública (según el modelo francés) y la adjudicación de una función tutelar y promotora por parte de los poderes públicos respecto a ellas.

En la anteriormente citada Real Orden de 17 de julio de 1839, el gobierno volvía a insistir a las autoridades provinciales sobre la necesidad de fomentar la creación de organismos ligados a los montes de piedad e incluso de fundarlos donde no los hubiese. Es importante la vinculación que se establece entre cajas y montes, ya que supone que el nuevo orden liberal-burgués reconocía el servicio que podían prestar todavía estas viejas instituciones, alejándolas de su carácter caritativo y uniéndolas a los fines de la beneficencia con el fin de garantizar la subsistencia de las clases populares urbanas y evitar, en buena parte, los conflictos sociales debidos al pauperismo. Por lo tanto, el Estado renunciaba a intervenir directamente sobre los fondos, optando por permitir que los ahorros de los humildes sirvieran para atender sus propias necesidades.

Estas iniciativas de carácter legislativo-normativo propiciaron la fundación de las primeras cajas: Granada (1839), Sagunto (1841), Sevilla, Santander, La Coruña y Valencia (1842), Barcelona (1844), Burgos y Cádiz (1845) y Vitoria (1850). Algunos años después se produjo una nueva intervención del gobierno a través del Real Decreto de 29 de junio de 1853, que fue la primera normativa de carácter general y que intentó regularlas de manera sistemática desde una perspectiva marcadamente uniformadora. Se pretendían los siguientes objetivos: el encargo de la gestión a las autoridades locales y provinciales de lo que se consideraría en adelante como establecimientos municipales de beneficencia, siguiendo las pautas marcadas por la Ley de Beneficencia de 20 de junio de 1849 que señalaba que dichos establecimientos únicamente podían ser públicos; siguiendo el modelo de actuación emprendida por los gobiernos franceses, se señalaba que la parte de capital que no se pudiese colocar en los montes de piedad

${ }^{y}$ Ver la Memoria de F. Quevedo y San Cristóbal (1835).

${ }^{10}$ En este sentido se pronunciaba Mesonero Romanos en el Diario de Avisos de Madrid, núm. 14, 15 de abril de 1835: «... Estas cajas son una institución esencialmente antirrevolucionaria que asocia al proletariado por medio de su propio trabajo al interés y a los goces de la propiedad y el orden.» 
se invertiría en la Caja de Consignaciones y Depósitos fundada por el ministerio de Bravo Murillo en 1852, en el contexto de reordenación de la deuda pública ${ }^{11}$ y apoyo a los gastos estatales; se regulaban las operaciones en cuanto a las cantidades que se podían depositar y los tipos de interés que remunerarían a los depósitos, los premios al ahorro, los fondos de reserva, etc., y se establecía la obligación de que se fundaran montes de piedad y, donde ya existieran estos institutos, se ordenaba la vinculación orgánica con las cajas.

Como han señalado Nadal-Sudriá ${ }^{12}$ y M. Titos ${ }^{13}$ este Decreto supuso un fuerte descalabro para la política intervencionista que en lo financiero seguían los poderes públicos antes de la revolución de 1854 , ya que contó con el rechazo frontal de los directivos de las indicadas entidades, produciéndose una retirada masiva de depósitos por parte de su clientela, al vislumbrar el peligro que suponía la inversión en deuda pública a través de la Caja de Depósitos ${ }^{14}$. Esta resistencia generó el cierre de algunas cajas y con ello la paralización de facto de las disposiciones del Decreto ${ }^{15}$, perviviendo de esta manera el particularismo estatutario y la autonomía de las mismas.

La situación precaria de la economía española, y más particularmente del sector financiero a mediados del siglo XIX, condicionó el desarrollo de las cajas debido a una serie de elementos como la estrechez de la oferta crediticia, la escasa relevancia del ahorro doméstico, la dirección del ahorro generado en el sector agropecuario hacia la inversión en la adquisición de nuevas propiedades, deuda pública o incluso en su atesoramiento en especie, la inversión en deuda del Estado del ahorro generado por los comerciantes, etc. Ello es atribuible en parte a la falta de incentivos que se desprendía de la Ley de Sociedades Anónimas de 28 de enero de 1848, la cual no facilitaba la constitución de este tipo de sociedades. En este contexto la escasez de oferta produjo un elevado precio del dinero, disparándose las tasas de interés y alcanzándose la primacía de los mercados

${ }^{11}$ Sobre este aspecto ver el artículo de Titos Martínez (1978), pp. 79-104.

12 J. Nadal y C. Sudriá (1983), pp. 58-59.

13 M. Titos Martínez (1991), pp. 14-15.

${ }^{14}$ B. Antón Ramirez (1876), pp. 176-179, señalaba al respecto: «... Los imponentes acostumbrados a la sencillez e independencia de las de Ahorros, se apresuraron a reclamar sus reintegros... logrando con ello paralizar tales medidas.»

${ }^{15}$ Mediante las Reales Órdenes de 2 de julio y 1 de agosto de 1853 se prorrogaba de manera indefinida el plazo de dos meses que daba el RD de 29 de junio de 1853 para la reforma de los Estatutos de las cajas y su adaptación a los preceptos establecidos en la mencionada normativa. 
informales de crédito. A partir de 1856 los gobiernos liberales progresistas adoptaron una serie de medidas tendentes a la liberalización del sector financiero ${ }^{16}$, logrando con ello cierta reactivación del mismo, aunque también se produjo la expansión en los ámbitos urbanos de las casas de préstamos que operaban a unos intereses desorbitados ${ }^{17} \mathrm{y}$ en el rural de los prestamistas-usureros que utilizaban su propio patrón de actuación, adecuado a la especificidad de la actividad agrícola. Las soluciones al grave problema de la usura, ligada a la estrechez de la oferta crediticia, el crecimiento de la demanda de capitales y la escasa penetración de los mercados formales del dinero, se concretaron en la propuesta de creación de instituciones de crédito especializadas para el ámbito rural (bancos de labradores) ${ }^{18}$ y el binomio cajas-montes para atender las necesidades de las clases bajas y medias de los ámbitos urbanos.

En esta primera etapa se fundaron 18 cajas y funcionaron hasta 16 montes de piedad ${ }^{19}$ que en 1868 se habían reducido a 16 y 14 , respectivamente. Ello se debe a que el tramo final de la misma coincidió con la crisis ferroviario-financiera de $1864-1868^{20}$ y con una serie de malas

${ }^{16}$ Ley de 1856 de Bancos de Emisión, que convertía al Banco de San Fernando en Banco de España y autorizaba el establecimiento de bancos de emisión en todas las provincias. Ley de 1856 sobre Sociedades de Crédito, que daba vía libre a la penetración de capital extranjero con destino a la financiación del ferrocarril y otras obras públicas y negocios privados. La Ley de 14 de marzo de 1856, que abolía la tasa de interés sobre el capital, dejando absoluta libertad en su fijación, etc.

${ }_{17} \mathrm{Al}$ respecto consultar el trabajo de M. Montero Canerero (1983), Bases para la investigación del préstamo y la usura en la sociedad del siglo XIX, Madrid, CECA, serie Monografías.

${ }_{18}$ Sobre este aspecto consultar A. P. Martínez Soto (1994), Crédito y aborro popular. El crédito agricola en la Región de Murcia, tesis doctoral en microfichas, Murcia, pp. 246-416. El primer proyecto arrancó con la Real Orden de 6 de abril de 1838 por la que se constituía una comisión para estudiar el problema del crédito en el sector agropecuario y concluyó con la Orden del Regente de 30 de septiembre de 1841 por la que se recomendaba la fundación de Bancos de Socorros para Labradores a partir de los capitales existentes en los Pósitos. Años después se ponia en marcha con la Real Orden de 15 de agosto de 1849 una Encuesta a organismos y particulares para recoger información sobre pesibles propuestas para organizar instituciones de crédito especializadas, resultado de todo lo cual fue la fundación de una serie de Bancos Agrícolas de vida efímera, así Banco Agrícola de Hellín (1854), Banco Agrícola Provincial de Pontevedra (1850), Banco Agrícola de Oviedo (1857). A partir de esas fechas hasta 1868 se produjeron una multitud de propuestas, muchas de las cuales no pasaron los primeros trámites parlamentarios.

19 B. Antón Ramírez (1876), pp. 197-198, señala que tiene noticias de la existencia de cajas de ahorros en Zaragoza, Cádiz, Santander, Palencia y Reus. Para ello utiliza la información que suministra la Enciclopedia Española de Derecho y Administración o Nuevo Teatro Universal, t. III, 1853, pp. 93-106, y el periódico La Correspondencia de España de 23 de marzo de 1876. También en esas fuentes, que está muy avanzado el proyecto de constituir una en Castellón de la Plana.

${ }^{20}$ Una explicación de las causas y efectos de esta crisis se encuentra en G. Tortella Casares (1973), pp. 242-292. 
cosechas que provocaron un hundimiento de la producción agrícola y como consecuencia la disminución de la entrada de depósitos. Estamos ante una típica crisis «mixta» cuyo impacto se extendió a todos los rincones de la economía, provocando la caída masiva de entidades de crédito y de las cotizaciones de la deuda pública. La misma Caja General de Consignaciones y Depósitos no pudo hacer frente a su pasivo y en su caída arrastró a aquellas cajas de ahorros que habían invertido capitales en ella, como en el caso de la Caja-Banco de Valencia ${ }^{21}$ que desapareció en 1867 ante el pánico desatado entre su clientela por la quiebra de la primera. El ritmo de creación de entidades se puede apreciar en el cuadro 1.

\section{CUADRO 1}

Cajas de aborros y montes de piedad que funcionaron durante el período 1839-1868

\begin{tabular}{|c|c|c|c|}
\hline \multicolumn{2}{|l|}{ Cajas de aborros } & \multicolumn{2}{|l|}{ Montes de piedad } \\
\hline Localidad & $\begin{array}{c}\text { Año } \\
\text { de fundación }\end{array}$ & Localidad & $\begin{array}{c}\text { Año } \\
\text { de fundación }\end{array}$ \\
\hline Barcelona ............................. & $1841-1844$ & Barcelona (Ntra. Sra. de & \\
\hline 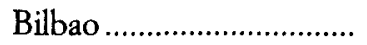 & 1861 & la Esperanza) ................ & 1750 \\
\hline Burgos .................................. & 1845 & Barcelona (Monte Pío & \\
\hline Cádiz .............................. & 1845 & barcelonés) .................... & 1845 \\
\hline 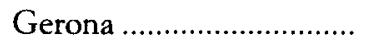 & 1864 & 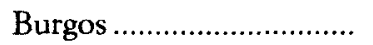 & 1845 \\
\hline 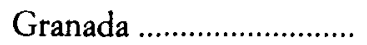 & 1839 & 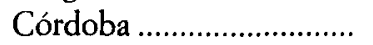 & 1864 \\
\hline Jerez de la Frontera ......... & 1862 & 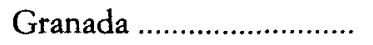 & $1740-1743$ \\
\hline 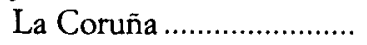 & 1842 & Jerez de la Frontera ......... & 1862 \\
\hline 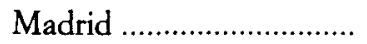 & 1839 & 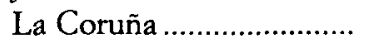 & 1842 \\
\hline Málaga ................................ & $1857-1863$ & 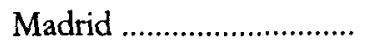 & 1724 \\
\hline Manresa............................ & 1865 & 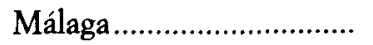 & $1856-1863$ \\
\hline Mataró................ & 1862 & 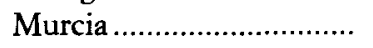 & 1729 \\
\hline Murviedro .... & 1841 & Murviedro ......................... & 1841 \\
\hline 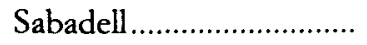 & 1859 & 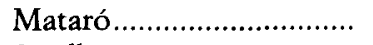 & 1859 \\
\hline 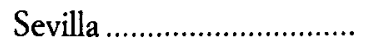 & 1842 & 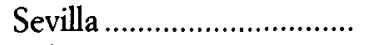 & 1842 \\
\hline Valencia ......... & 1851 & 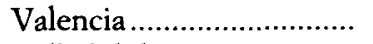 & 1851 \\
\hline Valladolid .. & 1841 & Valladolid .......................... & 1841 \\
\hline 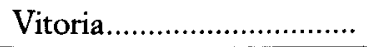 & 1850 & 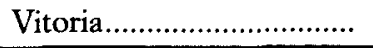 & 1856 \\
\hline
\end{tabular}

Fuentes: Memoria y Cuenta General del Monte de Piedad y Caja de Aborros de Madrid del año 1888 y B. Antón Ramírez (1876), pp. 187-198.

${ }^{21}$ Ver el trabajo de Clementina Ródenas (1978), pp. 54-58. 


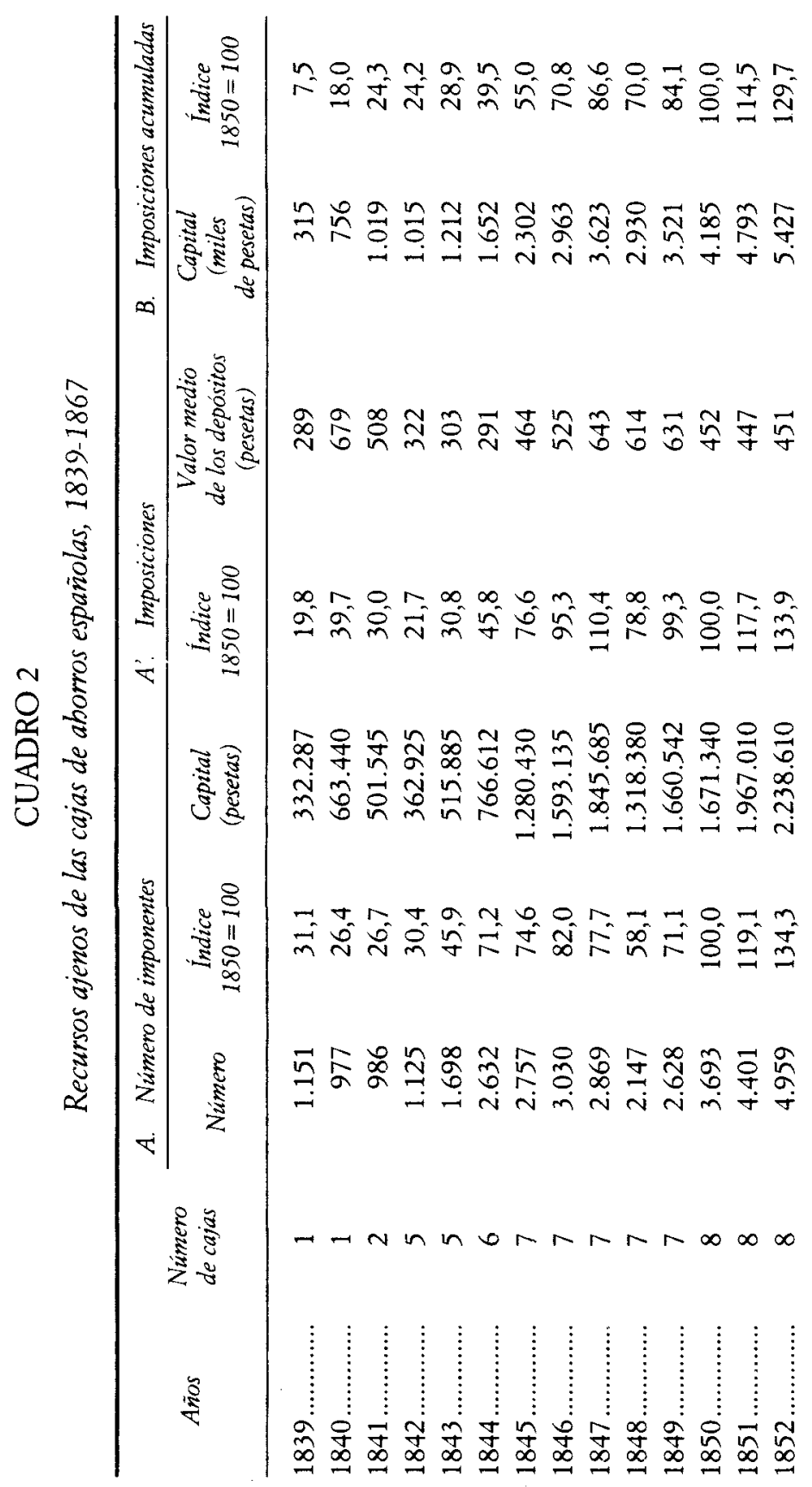




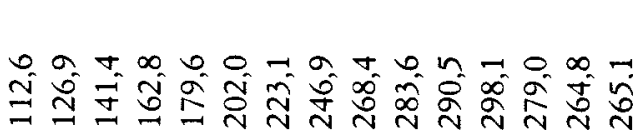

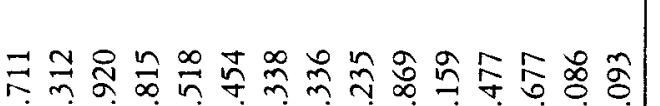

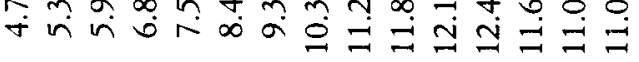

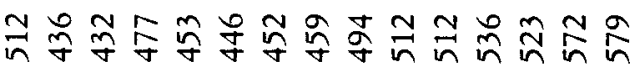

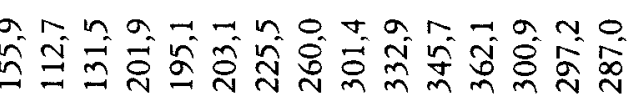

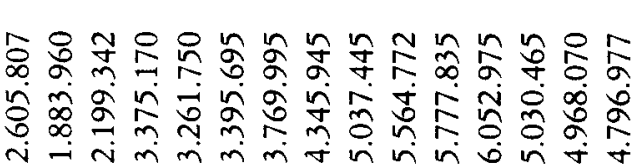

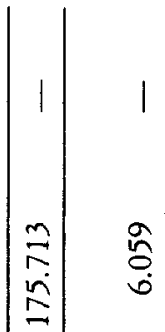

$\infty, \infty, 0,0,0,0, \pi n \nabla_{\infty}, n \sim$

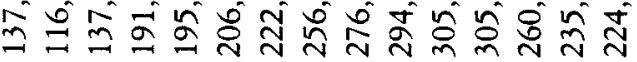

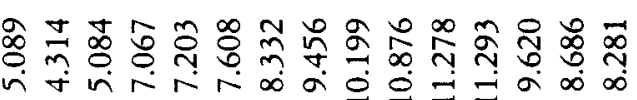


El mejor balance de este período inicial lo encontramos en las palabras de B. Antón Ramírez (propagandista y estudioso de las cajas, y gerente administrativo de la de Madrid) ${ }^{22}$ :

«... en la propagación de las Cajas de Ahorros... no veo la panacea que alcance a curar todos nuestros males sociales, creo firmemente que puede aliviarlos mucho; ser un recurso eficacísimo para dirigir por buen camino a la generación que nace; mejorar las costumbres y estimular al trabajo a las clases laboriosas; crear las modestas fortunas que contribuyan a la independencia y dignidad del hombre laborioso y, por consiguiente, al respeto de la propiedad ajena por amor a la propiedad propia... la acumulación de ahorro individual... contribuye a aumentar el número de familias acomodadas, haciéndolas inaccesibles a toda sugestión perturbadora, a disminuir la mendicidad y a evitar que muchos obreros inteligentes y laboriosos pasen el rubor de acudir a la caridad pública...».

La finalidad de las cajas de ahorros a la altura de 1868 estaba, pues, claramente perfilada como se desprende de esta y otras manifestaciones cualificadas. A destacar su carácter de institución de beneficencia y su función educativa entre las clases populares en temas como el ahorro, la defensa del nuevo orden social liberal y la actuación financiera como banca minorista. Los resultados en la captación de excedentes monetarios entre dichos grupos sociales se pueden apreciar en el cuadro 2.

En total las cajas habían captado depósitos por valor de 175,7 millones de pesetas, siendo el conjunto de nuevos ingresos en cada año 78,7 millones de pesetas procedentes 159.439 impositores. A un ritmo medio anual de 6.059.000 pesetas, con una incorporación media de 5.498 depositantes en cada año, con un saldo medio por cuenta de 494 pesetas, cifra que muestra la modestia de los ahorradores. Dentro de una evolución general positiva en la captación de clientela y capital, resaltan una serie de años de retroceso de carácter coyuntural relacionados con las crisis cíclicas: 1848 , 1854-1855 (en los que se produjo un intento de control de las cajas por parte de los poderes públicos a través del ya mencionado RD de 29 de junio de 1853, que dio lugar a la retirada de depósitos) y $1866-1867^{23}$,

${ }^{22}$ B. Antón Ramírez (1876), pp. XI-XIII.

${ }^{23} \mathrm{Al}$ referirse a ello B. Antón Ramírez (1876), p. 179, señala: «... la carencia de trabajo, la intranquilidad general y otras varias causas que concurrían a fines de 1867 y a principios de 1868 , hicieron que los pedidos de los reintegros se solicitaran en mayor número que de ordinario, y como por aquel entonces se trató de la conversión de los capitales de la Caja de Depósitos en bonos del Tesoro al 80 por cien, una gran parte de los imponentes confundió los nombres y esto contribuyó a que fuese mucho mayor la demanda». 
amén del arrastre negativo que supuso el hundimiento de la Caja General de Depósitos y Consignaciones.

\section{La oferta de crédito de los montes de piedad: el apoyo al consumo de las clases populares}

En las décadas de 1820-1830 los montes de piedad atravesaron un mal momento debido a la situación en la que habían quedado después de los años de guerra de Independencia y de desorden político ulterior. El emblemático Monte de Piedad de Madrid tenía reducidos sus fondos en 1828 a tan sólo 1.265 .000 reales y el impago de los sueldos de sus funcionarios llegó a una cifra próxima a medio millón de reales ${ }^{24}$; la situación se agravaba debido a la existencia de múltiples préstamos denominados «imaginarios» o impagados. Hacia 1838 se inició la recuperación debido en parte al mandato de las Cortes de ese año que suprimieron la dotación a cargo del Estado y facultaron a la institución para imponer sobre los préstamos el 6 por 100 de interés, para que de esta manera volviese a disponer de sus fondos de reserva. En 1839 con la aparición de la Caja de Ahorros de Madrid y la obligación de invertir los depósitos en préstamos al Monte éste salió de su letargo adquiriendo nueva vida, como lo indican la recuperación de las operaciones (cuadro 3 ).

La modalidad de préstamos sin interés cubría las demandas del grupo menos favorecido de las clases populares urbanas. Se trataba de préstamos ínfimos con un valor medio de 156 reales, los cuales constituían una práctica residual basada en principios de caridad que se apoyaba en la provisión de fondos que el Monte obtenía de las Cortes. Ante las dificultades que podía pasar la Caja al ceder capitales al Monte que prestaba sin interés, los poderes públicos establecieron una tasa de interés del 5 por 100 para retribuir los capitales invertidos por ella. De esta manera se concedieron por el Monte entre 1833-1837 un total de 123.405 préstamos con interés, por un valor de 36,9 millones de reales, con un valor medio por operación de 300 reales. El primer tipo de operaciones crediticias fueron retrocediendo a partir de dicha fecha, realizándose en los referidos años un total de 58.906 por un valor de 9,1 millones de reales, siendo el valor medio de las mismas de 156 reales, cifras sensiblemente inferiores a la otra moda-

${ }^{24}$ Sobre la evolución de los montes de piedad en este periodo ver B. Antón Ramírez (1876), pp. 71-94. 


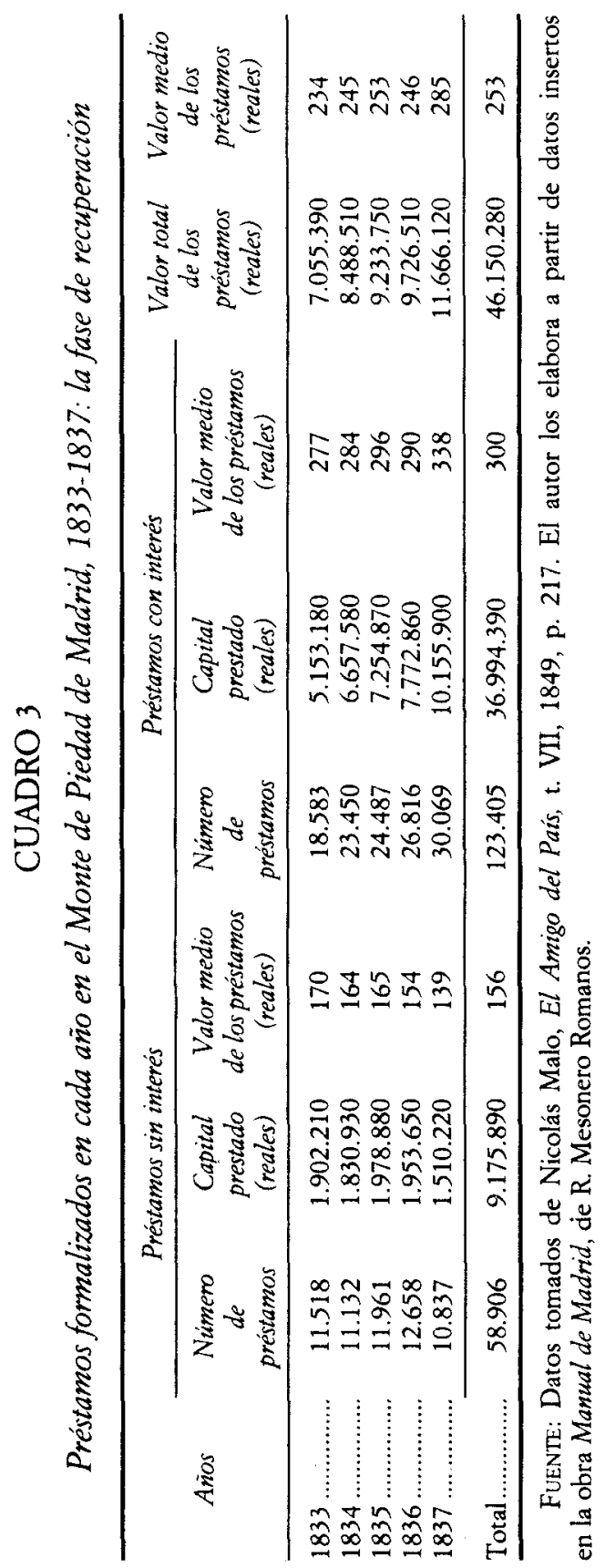


lidad. Estamos ante una clara redefinición del sentido y finalidad del binomio Caja-Monte, en la línea de sustituir la orientación de caritativa por otra de carácter benéfico-social. El uso del interés y la relación con la Caja permitió la rápida recuperación de los fondos de reserva del Monte, que subieron de 1,4 millones de reales en 1840 a 7 millones en 1868 .

Entre 1841-1868 se tienen noticias del funcionamiento de 16 montes de piedad (ver cuadro 1), la mayor parte de los cuales se fundaron ligados a las cajas de ahorros. Incluso algunos de ellos, como en el de Nuestra Señora de la Esperanza de Barcelona, admitían depósitos, tanto sin interés como con uno módico, y la mayoría realizaban préstamos con cantidades de escasa cuantía, desde 4 a 100 reales, con carácter de socorro. Por término medio las tasas de interés aplicadas se situaban entre el 3 y el 6 por 100 , dependiendo del valor y de las garantías empeñadas en la operación. La información existente sobre la actuación del conjunto de establecimientos en el período 1839-1868 es muy sesgada e incompleta, disponiéndose tan sólo de datos para los años 1862-1867, siendo los resultados los que se pueden apreciar en los cuadros 4 y 5 .

A lo largo del período 1862-1867 se fue gestando la crisis financiera, social y política aludida anteriormente, que afectó a la oferta de dinero. Ello se refleja en la paulatina caída del capital adelantado por los montes; en términos absolutos, la cifra fue de 21.082 .120 reales, aunque el número de préstamos otorgados creciera ante la demanda de las clases populares urbanas afectadas por la crisis, alcanzándose el número de 64.994 operaciones. El promedio anual de las liquideces comprometidas en esos años ascendió a 109,1 millones de reales en 196.139 operaciones de crédito. La tasa de variación del total del capital prestado es del $-17,6$ por 100 , lo que muestra los efectos de las turbulencias económicas, situación que afectó más aún a los préstamos concedidos sobre papel, con una tasa de variación del $-31,5$ por 100 , debido a la caída de valor de este tipo de garantías.

Los préstamos se realizaban en dos modalidades diferentes, por un lado los «empeños de ropas y albajas» que constituían la variedad que solía utilizar mayoritariamente la clientela perteneciente a las clases populares y, por otro, los préstamos con «garantía de papel» (Bonos del Estado, acciones, obligaciones, etc.) que era utilizada por elementos de las clases medias urbanas. La primera categoría suponía el 98,7 por 100 de las operaciones (media anual de 193.777 en el período considerado), y la segunda tan sólo el 1,3 por 100 (2.362). Si atendemos al capital prestado en cada una de estas variedades comprobamos el mayor peso de la segunda, que supuso 


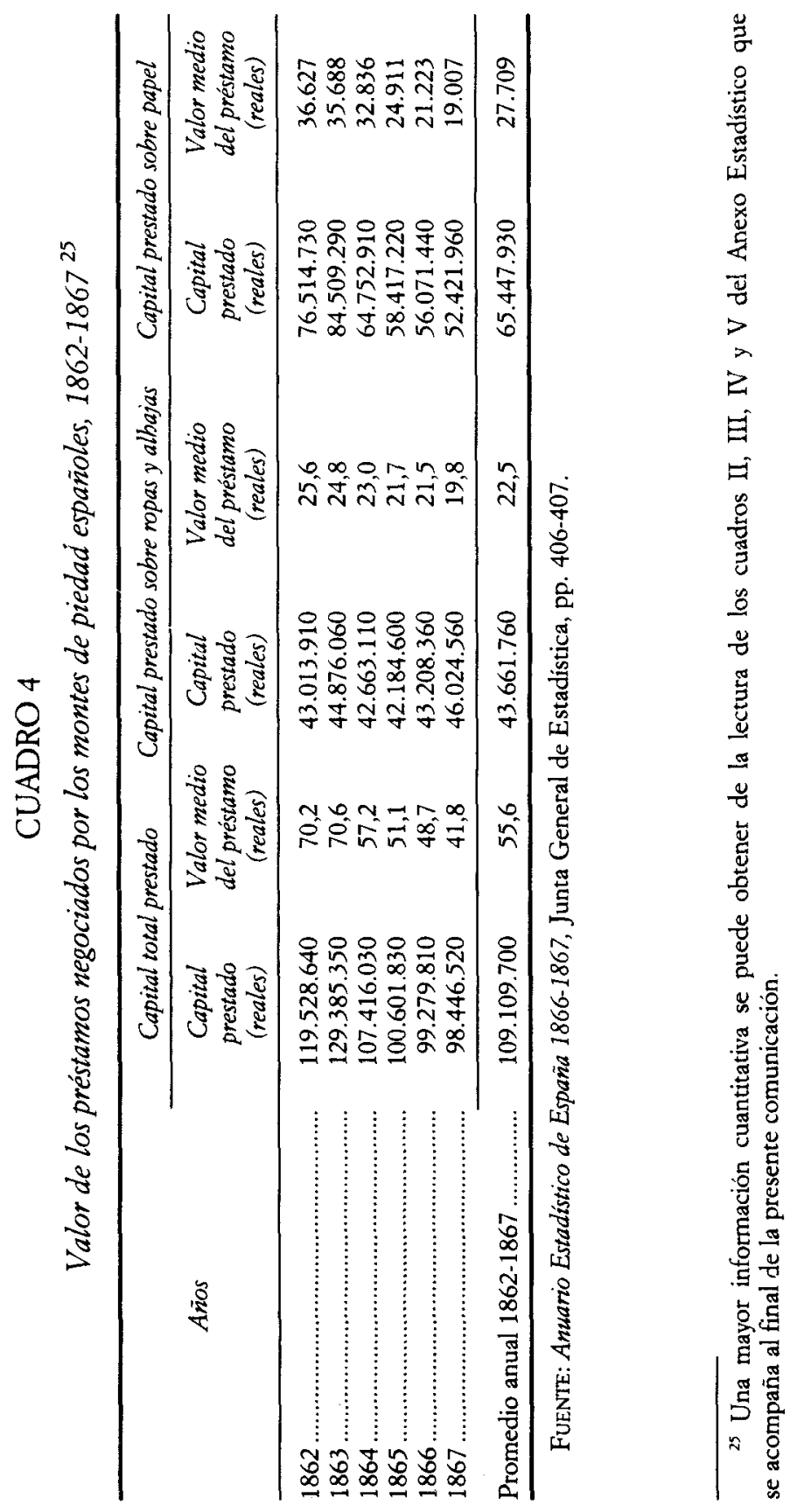




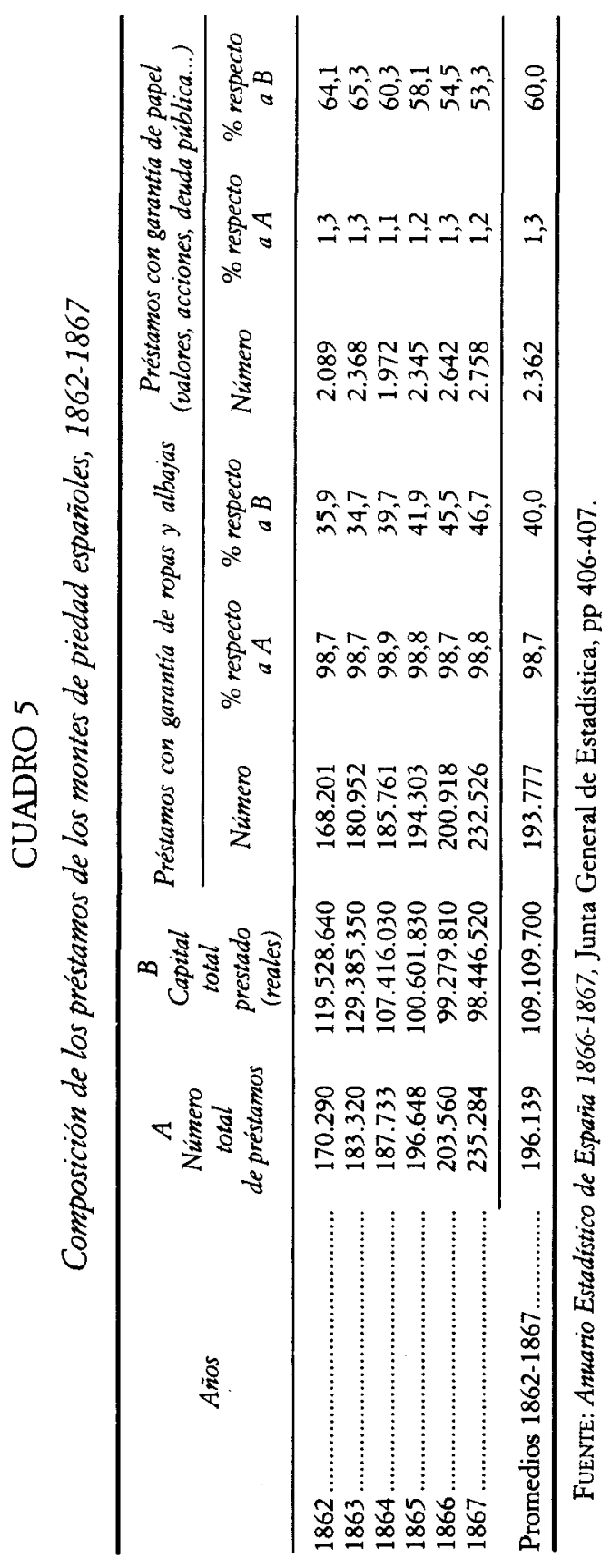


casi el 60 por 100 del líquido negociado por término medio; en total 65.447.930 reales, frente a 43.661 .760 en la variedad de empeños de alhajas y ropas. Esta situación muestra claramente cómo los montes colocaban su capital mayoritariamente en operaciones destinadas a satisfacer la demanda de crédito de una clientela proveniente de las nacientes clases medias urbanas, la cual podía avalar sus peticiones con garantías de considerable valor. La cuantía media de los préstamos concedidos con garantía de papel alcanzó la cifra de 27.708 reales, frente a los 225 reales de los empeños sobre ropa y alhajas. Por lo tanto, estamos ante una contradicción entre la dinámica de funcionamiento y los objetivos que tenían encomendados los montes, situación que puede resumirse diciendo que se trata de una clientela mayoritaria procedente de las capas sociales más desfavorecidas de las ciudades pero que al mismo tiempo se registra una colocación preferencial de capital entre la burguesía media urbana $^{26}$.

\section{«La banca del pobre» ${ }^{27}$ : composición de la clientela de las cajas}

Otro elemento importante lo constituye la configuración de la clientela de las cajas, cuyo conocimiento ayuda a responder a la pregunta de si utilizaron sus servicios aquellos grupos sociales para los que iban destinadas. No se dispone de datos generales y seriales que permitan responder este interrogante, aunque sí de algunos referentes parciales como el de la Caja de Ahorros de Madrid, que autoriza una aproximación fiable. En el cuadro 6 tenemos una visión de conjunto de la composición socioprofesional de la clientela de las cajas para el año 1867 .

La distribución socioprofesional y de género muestra un predominio de grupos sin oficio; así mujeres y niños suponen el 38,2 por 100 de la misma, en este caso se trata de ahorro familiar que se detrae del consumo y se destina a prevenir futuras situaciones difíciles (enfermedades, bodas -ingresos dotales-, estudios, etc.). Siguen después los jornaleros con el 23,7 por 100 y los trabajadores domésticos con el 17,7 por 100 , lo cual es un indicador del relativo éxito de la difusión de las «virtudes»

${ }^{26}$ Para el caso de las cajas catalanas J. Nadal y C. Sudriá (1983), pp. 61-61, y G. Chastagneret (1966), pp. 232-236, confirman esta tendencia, por la que algunas entidades buscaron colocaciones más rentables que los pequeños empeños o los depósitos en la Caja de Depósitos y Consignaciones, entre industriales del textil.

${ }^{27}$ Expresión utilizada por J. J. Proudhon, citada por D. Duet (1981), p. 41. 


\section{CUADRO 6}

Catalogación socioprofesional y de género de los impositores de las cajas de aborros españolas, 1867 (porcentajes)

\begin{tabular}{|c|c|c|c|c|c|c|c|}
\hline \multirow{2}{*}{ Caja } & \multirow{2}{*}{ Domésticos } & \multirow{2}{*}{ Jormaleros } & \multirow{2}{*}{ Empleados } & \multirow{2}{*}{ Militares } & \multirow{2}{*}{$\begin{array}{l}\text { Oficios } \\
\text { varios }\end{array}$} & \multicolumn{2}{|c|}{ Sin oficio } \\
\hline & & & & & & Mujeres & Menores \\
\hline Vitoria.......................... & 18,9 & 21,8 & 2,1 & 0,7 & 5,1 & 31,3 & 19,7 \\
\hline Barcelona ........................... & 14,2 & 36,6 & 0,5 & 1,3 & 13,0 & 21,7 & 12,5 \\
\hline Manresa & 11,1 & 26,6 & - & 2,2 & 42,2 & 6,6 & 11,1 \\
\hline Mataró.... & 13,3 & 26,6 & - & - & 24,4 & 20,0 & 15,5 \\
\hline Sabadell ............................ & . 4,6 & 3,6 & - & - & 64,2 & 7,3 & 20,2 \\
\hline Gerona ............................ & 18,8 & 2,0 & - & - & - & 45,8 & 33,3 \\
\hline Cádiz ........................ & 16,0 & - & - & 8,0 & 28,0 & 44,0 & 4,0 \\
\hline Jérez de la Frontera .... & 18,7 & 8,3 & 6,25 & - & 29,1 & 25,0 & 12,5 \\
\hline Burgos ............................ & 10,2 & 8,3 & 7,8 & 6,3 & 44,4 & 16,1 & 6,8 \\
\hline 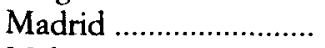 & 25,1 & 21,3 & 5,9 & 3,1 & 5,6 & 22,9 & 15,9 \\
\hline 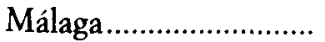 & . 2,1 & 16,6 & 13,5 & 1,0 & 12,5 & 42,7 & 11,4 \\
\hline 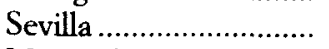 & 3,4 & 9,2 & 8,8 & 4,1 & 28,4 & 43,0 & 3,0 \\
\hline Murviedro ........................ & 4,9 & 22,4 & 2,4 & - & 21,9 & 34,1 & 9,7 \\
\hline Valladolid ............................ & . 12,6 & 21,3 & 7,9 & 3,2 & 14,5 & 26,3 & 14,1 \\
\hline Bilbao ............................... & . $\quad 0,4$ & 4,1 & 10,2 & - & 50,2 & 33,5 & 1,6 \\
\hline Estado. & 17,7 & 23,7 & 4,9 & 2,6 & 12,6 & 24,9 & 13,3 \\
\hline
\end{tabular}

FuENTE: Anuario Estadistico de España 1866-1867, Junta General de Estadística, pp. 370-371.

del ahorro. El segundo grupo citado, los trabajadores domésticos, tenía una situación laboral muy específica, ya que recibían en especie los bienes de subsistencia necesarios (vestido, vivienda, comida, etc.), lo que facilitaba la posibilidad de ahorrar su salario en metálico con vistas a la vejez o al matrimonio; al tiempo, esta práctica les ponía más en contacto con la moral y estilo de vida de la burguesía y por tanto con los hábitos de ahorro. El resto de la nómina de clientes está compuesto por empleados, militares y trabajadores de otros sectores productivos.

La jerarquía de situaciones varía en otras cajas; así, en la de Madrid, el grupo de trabajadores domésticos está por encima de la media estatal, mientras que en las catalanas (Barcelona, Sabadell, Mataró y Manresa) el predominio de los jornaleros y trabajadores industriales es manifiesto respecto a la media del conjunto, hecho que también sucede con las enti- 


\section{CUADRO 7}

Composición socioprofesional y de género de los impositores del Monte de Piedad y Caja de Aborros de Madrid entre 1839-1873

\begin{tabular}{|c|c|c|c|}
\hline \multicolumn{2}{|c|}{ Composición de género de los imponentes } & Número & Porcentaje \\
\hline \multirow{4}{*}{ Mujeres: } & 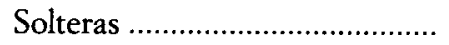 & 7.527 & 7,65 \\
\hline & 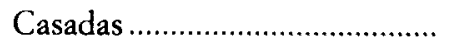 & 11.461 & 11,65 \\
\hline & 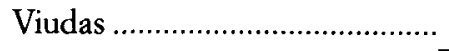 & 6.196 & 6,30 \\
\hline & 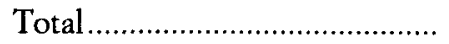 & 25.184 & 25,60 \\
\hline \multirow{3}{*}{ Menores: } & Varones ................................... & 9.631 & 9,79 \\
\hline & Hembras ................................. & 9.564 & 9,73 \\
\hline & 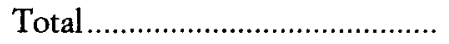 & 19.195 & 19,52 \\
\hline \multicolumn{2}{|c|}{ Composición socioprofesional de los imponentes } & Número & Porcentaje \\
\hline \multirow{3}{*}{ Domésticos: } & 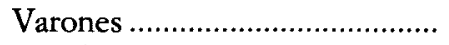 & 6.387 & 6,49 \\
\hline & Hembras .................................... & 14.029 & 14,27 \\
\hline & 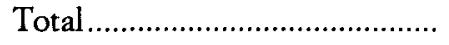 & 20.416 & 20,76 \\
\hline \multicolumn{2}{|c|}{ 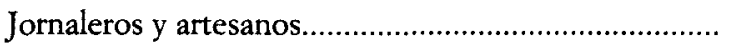 } & 18.800 & 19,12 \\
\hline \multicolumn{2}{|c|}{ 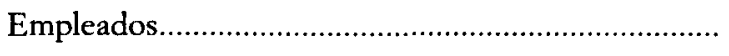 } & 5.590 & 5,68 \\
\hline \multirow{3}{*}{ Militares: } & 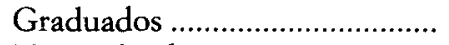 & 1.207 & 1,23 \\
\hline & No graduados .. & 1.596 & 1,62 \\
\hline & (.......................... & 2.803 & 2,85 \\
\hline \multicolumn{2}{|c|}{ 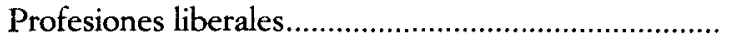 } & 929 & 0,94 \\
\hline \multicolumn{2}{|l|}{ Varios ..... } & 5.009 & 5,09 \\
\hline \multicolumn{2}{|l|}{ Total. } & 98.298 & 100,00 \\
\hline
\end{tabular}

Fuente: Memoria y Cuenta General del Monte de Piedad y Caja de Aborros de Madrid correspondiente al año 1881, pp. 110-112. 
dades de Bilbao, Jerez de la Frontera y Sevilla. La mujer constituye el principal agente de ahorro entre las clases populares. Suponía el 25,58 por 100 de la clientela de la caja, produciéndose diferencias significativas según el estado civil, con predominio de las casadas, que sumaban el 11,65 por 100 del total de la clientela. En cuanto al grupo de los niños, representaba el 19,52 por 100, cifra considerable dentro del conjunto. Sobre este grupo se centraron distintas actuaciones de carácter educativo; así, desde el principio hubo un considerable interés por parte de los propagandistas y dirigentes de las cajas para difundir la modalidad de ahorro escolar a través de las denominadas «cajas escolares de aborros» ${ }^{28}$, cuya misión fundamental era según B. Antón ${ }^{29}$ :

«... La escuela no solamente debe enseñar, sino educar, sobre todo a los niños de las clases pobres y a los de los obreros de las fábricas, porque son los que menos educación pueden recibir en el seno de las familias... se trata de difundir e inculcar el instinto de economía entre los niños que frecuentan las escuelas primarias... tratando el ahorro como elemento de moralización.»

También algunas cajas ofrecieron a sus clientes cuentas especiales para niños, conocidas como dotales infantiles, en las cuales el propio establecimiento realizaba una primera imposición simbólica cuando se abría la cuenta para un neonatal y estaban sometidas a condiciones especiales en cuanto a los reintegros. Se trataba obviamente de potenciar la labor educativa, a través de intervención sobre las nuevas generaciones.

El siguiente grupo de la nómina lo constituyen los trabajadores del servicio doméstico, que en la capital formaba un subsector laboral muy numeroso, en consonancia con el carácter y configuración de centro administrativo y financiero de la ciudad. Representaba el 20,76 por 100 de la clientela y dentro del mismo la mujer volvía a predominar con el 14,27 por 100 , lo cual parece lógico dada la hegemonía femenina en este tipo de profesión. Los trabajadores industriales y artesanos ascendian al 19,12 por 100 del total, porcentaje inferior al registrado en las cajas de Barcelona y ciudades de su área de influencia (Mataró, Sabadell y Manresa), donde el proletariado de la industria textil tiene una mayor presencia debido a

${ }^{28}$ Esta modalidad de ahorro se inició en Bélgica dentro del sistema educativo, contando con la colaboración de los maestros. El creador del sistema fue $\mathrm{H}$. Laurent, profesor de Derecho Civil de la Universidad de Gante. Sobre este aspecto ver B. Antón Ramírez (1876), pp. 219-226.

${ }^{29}$ Antón Ramírez (1876), p. 221. 
la mayor capacidad de excedente que les ofrecían sus salarios reales. La pequeña burguesía y los trabajadores cualificados también figuran en la nómina a través de los empleados, funcionarios, militares y profesiones liberales, que en conjunto suponían el 9,47 por 100 . Se puede concluir, pues, que las cajas habían atraído al tipo de clientela para la que fueron creadas, aunque su extensión y capacidad de penetración entre estos grupos eran aún muy limitadas en el período al que nos estamos refiriendo. En 1877 la cifra de imponentes por cada 100 habitantes era de 0,33 , que comparada con la de países como Dinamarca $(36,7)$, Bélgica $(26,7)$, Francia $(27)^{30}$ e incluso Italia $(4,3)$ resulta muy pequeña.

\section{EL FUNCIONAMIENTO DE LAS CAJAS DE AHORROS ENTRE 1868-1904}

La función real que desempeñaron las cajas durante este período fue la de captación del ahorro de forma especializada y, en menor medida, la de banca al por menor. El cumplimiento de su cometido fue posible porque reunían una serie de condiciones que pueden resumirse como sigue: la territorialidad o delimitación de su espacio físico de actuación, que constituyó una estrategia eficaz, pues limitaba los riesgos de las operaciones debido al control y conocimiento de la clientela; la asunción de su carácter de entidad de beneficencia y moralizante; la especialización en la captación de los excedentes de renta entre los grupos sociales medios y bajos de la sociedad, labor para la que fueron creadas. Esto conllevaba el desarrollo de actuaciones que propiciaron el estímulo del ahorro entre los mencionados grupos sociales en el ámbito de cada ciudad concreta; el despliegue de una labor de integración en los circuitos financieros de los fondos propios, trasladándolos a los centros de inversión. Las entidades ofrecían, por primera vez, la posibilidad de invertir pequeños capitales con cierto nivel de rentabilidad; el desarrollo de estrategias específicas de atracción de la clientela. El establecimiento de la cartilla de ahorro ${ }^{31}$ constituyó un hito, ya que permitía disfrutar de la sensación de titularidad, rentabilidad y dis-

30 Las cifras están tomadas de A. Bosc (1909), p. 45.

${ }^{31}$ Las libretas al portador fueron una innovación procedente de Italia, donde la Caja de Ahorros de Milán las había implantado en su Reglamentc de 18 de marzo de 1863. Sobre este aspecto ver la Memoria y Cuenta General del Monte de Piedad y Caja de Aborros de Madrid del año 1884, pp. 107-108. 
ponibilidad de los ahorros propios; la defensa del orden social, convirtiendo a los clientes de las clases populares en propietarios de un «capital»y, por lo tanto, de un activo económico contingente sensible al desorden y conflicto social; la contribución al desarrollo económico y al bienestar social. Las cajas fueron a la vez producto y causa del crecimiento económico, participando en la extensión del mercado formal de crédito y en la formación de capital; la aportación de las entidades al crecimiento discurrió por la vía de la inversión y del consumo, y la colaboración, al final del período, con el sector público a través de la colocación de los fondos en deuda pública.

Forniés Casals ha denominado a esta etapa de la historia de las cajas con el apelativo de fase de perentoriedad social ${ }^{32}$, debido a la estrecha relación que establecieron con los montes de piedad. A reseñar que, en cuanto a la ordenación legislativa, tan sólo se registran dos actuaciones de interés en el período 1868: en primer lugar, al Real Decreto de 27 de abril de 1875 (refrendado por el Ministro de Gobernación), el cual en su artículo $5 .^{\circ}$ definía cuáles eran las entidades de beneficencia de utilidad pública, figurando entre ellas las cajas de ahorro y montes de piedad. Una nueva iniciativa legislativa, esta vez más sólida, se efectuó con la Ley de 29 de junio de 1880 que favoreció la fundación de un buen número de entidades (de 16 existentes en 1867 se pasó a 49 en 1900). La Ley desarrollaba una línea no intervencionista de los poderes públicos visto el anterior fracaso del Real Decreto de 1853, concretándose en una serie de premisas recogidas en el articulado, entre las que destacamos las siguientes: se promueve la fundación de cajas y montes en todas las provincias donde no existan; el gobierno se reserva la potestad de aprobar los reglamentos de las mismas, lo que implica el ejercicio de cierto control sobre su funcionamiento; se ratifica la calificación de las cajas y montes como instituciones de beneficencia, colocándose así bajo la protección gubernamental, lo que autoriza la exención fiscal en sus operaciones; se recomienda el funcionamiento conjunto y dependiente de ambos, aunque podrían trabajar de manera separada en el caso de contar con fuentes de colocación de los depósitos las primeras y de aprovisionamiento de capitales los segundos; dentro de la labor educativa y difusora del ahorro que venían desempeñando, la Ley disponía que se promovieran cajas esco-

\footnotetext{
${ }^{32}$ Así la denomina en un trabajo J. Francisco Forniés Casals (1991), p. 43.
} 
lares en los centros de enseñanza y que éstas estuvieran conectadas a las cajas de ahorro de sus correspondientes localidades ${ }^{33}$.

\section{La captación de depósitos de ahorro}

Las fuentes disponibles para este período son todavía escasas. Prácticamente se limitan a las Memorias y Cuentas Generales del Monte de Piedad y Caja de Aborros de Madrid, los Anuarios Estadísticos de España y las cifras elaboradas con posterioridad por algunas Memorias de la Caja Postal de Aborros de España. De todas, la más utilizada ha sido la primera, pero para ello ha sido preciso realizar procesos de depuración de los datos, así como la extrapolación de los mismos en el caso de algunos establecimientos y durante determinados años, por carecer de información precisa $^{34}$. Los resultados generales agrupados por quinquenios son los siguientes (cuadro 8):

${ }^{33}$ En este sentido la expansión fue rápida en algunas ciudades, así, según la Memoria y Cuenta General del Monte de Piedad y Caja de Aborro de Madrid de 1884, en 1883 existian en nuestro país las siguientes cajas de ahorros escolares:

\begin{tabular}{|c|c|c|c|}
\hline Ciudad & $\begin{array}{l}\text { Escuelas } \\
\text { con cajas }\end{array}$ & Imponentes & $\begin{array}{c}\text { Capital impuesto } \\
\text { (pesetas) }\end{array}$ \\
\hline 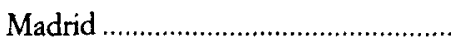 & 56 & 796 & 28.462 \\
\hline 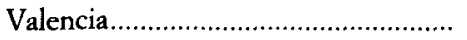 & 31 & 647 & 24.176 \\
\hline Sevilla & 21 & 417 & 16.626 \\
\hline Palma de Mallorca .................................. & 8 & 159 & 2.149 \\
\hline 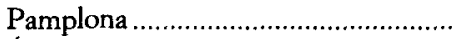 & 1 & 442 & 5.325 \\
\hline 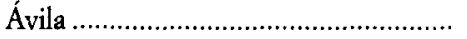 & 6 & 156 & 5.044 \\
\hline 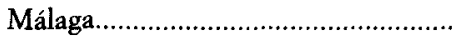 & 5 & 44 & 718 \\
\hline Oviedo & 2 & 42 & 352 \\
\hline
\end{tabular}

Esta cantidad resulta raquítica si se compara con las existentes en Francia en esa misma fecha: 8.033 escuelas, con 176.040 libretas, con 2.984 .352 pesetas.

${ }^{34}$ Gabriel Tortella (1974) estudió y trabajó esta fuente, elaborando el conocido trabajo «Una serie de cuentas de ahorro no bancarias, 1874-1914» a escala provincial en el trabajo colectivo La banca española en la Restauración, II, Datos para una bistoria económica, Madrid, Banco de España, pp. 541-549. 


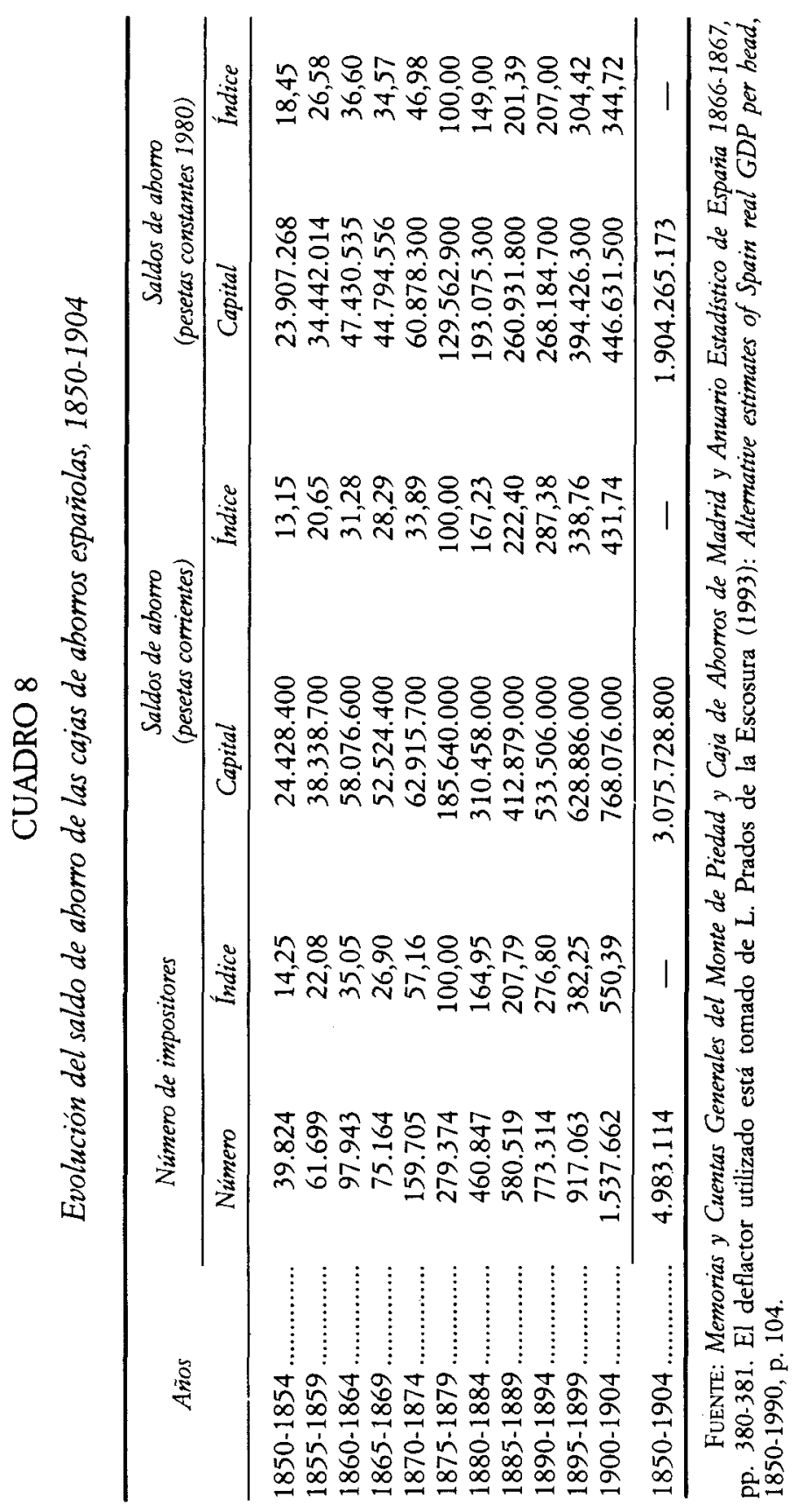


Los datos muestran una evolución ascendente continuada durante todo el período 1850-1904 tanto en lo relativo al número de imponentes como al capital depositado. El primero alcanzó un total de 4,8 millones, cifra que expresa el importante aumento experimentado desde los 22.456 del quinquenio 1850-1854, a los 1,5 millones del transcurrido entre 1900 y 1904. Tan sólo se experimenta retroceso durante los años 1865-1869 con una caída relativa del $-19,4$ por 100 , producto de la ya citada crisis financiera; incluso la depresión finisecular no supuso un cambio de tendencia. En cuanto al segundo, cuyo total suma 3.075 millones de pesetas constantes (1.904 millones en pesetas de 1980), tampoco acusó las sucesivas crisis $^{35}$.

Para valorar la importancia de los recursos ajenos manejados por las cajas de ahorros parece conveniente remitirnos a lo que sucede con el resto de productos del mercado nacional de depósitos (cuadro 9). Los datos presentados ponen de manifiesto que los depósitos de las cajas fueron superiores a los de la banca privada (en sus modalidades de cuentas de depósitos y de ahorro). Tan sólo quedan por debajo si se les compara con los capitales existentes en las cuentas corrientes agregadas de la banca privada, conociendo un mínimo en $1874-1878$ con el 36,67 por 100 y el máximo en 1889-1893 con el 75,38 por 100. Los porcentajes correspondientes a los depósitos de las cajas de ahorros dentro del conjunto de depósitos del sistema financiero se mantuvieron bastante estables durante esos treinta años, en torno al 13,75 por 100 , alcanzando el máximo en el quinquenio $1879-1883$ con el 14,51 por 100 . El logro conseguido parece considerable, ello constituye un buen indicador del papel relevante de dichas entidades desde fechas muy tempranas, como señalaba $\mathrm{M}$. Titos ${ }^{36}$.

Superada la crisis de 1882 , que afectó fundamentalmente a la banca privada, el volumen total de las cuentas de ahorro alcanza su techo en 1887, estancándose prácticamente hasta la Primera Guerra Mundial. Posiblemente este estancamiento tenga que ver con la reforma de Camacho de 1882 , a consecuencia de la cual los activos semilíquidos (especialmente la deuda pública) comenzaron a resultar más atractivos que los tipos de interés de las cajas, lo que les enajenó la parte más solvente de su clientela. En el caso de Cataluña la decadencia de la banca privada dio paso a la

${ }^{35}$ Tan sólo una serie de años aislados presentaron un balance negativo durante el período de la crisis finisecular atendiendo al volumen expresado en pesetas constantes: 1883,1888 , 1892,1897 y 1898.

${ }^{36}$ M. Titos (1991), p. 19. 


\section{CUADRO 9}

Evolución de la participación de los depósitos de las cajas en el conjunto de depósitos del sistema financiero español, 1874-1903

\begin{tabular}{|c|c|c|c|}
\hline Años & $\begin{array}{c}\text { A } \\
\text { Porcentaje } \\
\text { de los depósitos } \\
\text { de las cajas sobre } \\
\text { las cuentas } \\
\text { corrientes agregadas } \\
\text { de la banca privada }\end{array}$ & $\begin{array}{c}\text { B } \\
\text { Porcentaje } \\
\text { de los depósitos } \\
\text { de las cajas sobre } \\
\text { el conjunto } \\
\text { de depósitos } \\
\text { en la banca privada }\end{array}$ & $\begin{array}{c}C \\
\text { Porcentaje } \\
\text { de los depósitos } \\
\text { de las cajas de aborros } \\
\text { respecto al conjunto } \\
\text { de depósitos } \\
\text { del sistema financiero }\end{array}$ \\
\hline $1874-1878$. & 36,67 & 30,12 & 12,64 \\
\hline $1879-1883 \ldots \ldots \ldots \ldots \ldots$ & 43,94 & 33,56 & 14,51 \\
\hline $1884-1888 \ldots \ldots \ldots \ldots \ldots$ & 63,85 & 42,21 & 14,41 \\
\hline $1889-1893 \ldots \ldots \ldots \ldots \ldots$ & 75,38 & 47,65 & 14,50 \\
\hline $1894-1898 \ldots \ldots \ldots \ldots \ldots$ & 71,42 & 44,92 & 14,41 \\
\hline $1899-1903 \ldots \ldots \ldots \ldots \ldots$ & 61,66 & 36,75 & 12,05 \\
\hline
\end{tabular}

B: Los depósitos en la banca privada se conforman con: cuentas corrientes agregadas + depósitos de ahorro + imposiciones en caja de ahorros.

C: Los depósitos del conjunto del sistema financiero: depósitos de banca privada + depósitos en Banco de España.

Fuente: Cuadro 8 . Los datos referidos a la banca privada y al conjunto del sistema financiero están tomados de Gabriel Tortella (1974), pp. 490 y 499.

preponderancia de aquéllas, produciéndose un traspaso de recursos. La tasa de crecimiento medio anual del conjunto de los depósitos de las cajas de ahorros (benéficas y bancarias) entre 1874-1894 fue del 9,7 por 100, pero en el caso de las primeras ${ }^{37}$ el crecimiento fue mucho menor. De esta manera, aunque el ritmo se desacelera entre 1894-1903, se había conseguido ya una tasa media anual del 4,3 por 100 , bajando hasta el 2,7 por 100 en los años finales de siglo.

\section{Caracterización de los recursos ajenos de las cajas de ahorros}

Otros datos que pueden interesarnos para poder situar mejor el alcance de los resultados obtenidos son - como se señaló en la introducción-, los concernientes a la distribución territorial de los depósitos, la valoración de las cuentas de ahorro, el peso relativo de la clientela dentro del conjunto

${ }^{37}$ Ver sobre este aspecto G. Tortella (1974), p. 503. 
de la población, la posición del volumen alcanzado por los depósitos en relación a una serie de magnitudes agregadas de carácter general (Renta nacional, Presupuestos del Estado, etc.) y la comparación con los sistemas de cajas de países próximos. En cuanto a la distribución territorial de los depósitos la situación es la que aparece en el cuadro 10 .

Destaca la aportación del Monte de Piedad y Caja de Ahorros de Madrid durante todo el período, con una claro predominio en cuanto a la captación de recursos ajenos. Dentro de esta tendencia general hay que delimitar dos subperíodos diferenciados; por una lado el comprendido entre 1875-1885, durante el cual los depósitos de la entidad madrileña estaban por encima del 50 por 100 del total, con un máximo en $1885(60,4$ por 100 ), y, por otro, 1890-1900, a partir del cual se experimenta una tendencia descendente, pasando los depósitos a representar un 32 por 100 del total. La normalización de la entidad en $1875^{38}$ producto de la nueva fase de recuperación económica que vivía el país, así como la estabilidad política que supuso la restauración borbónica, abrió paso a una etapa de crecimiento cuyo punto álgido se alcanzó en 1887 cuando la caja logre unos depósitos por valor de 52,9 millones de pesetas, cifra que no se superó hasta 1915. Esta situación permitió el despegue de un proceso inversor tendente a consolidar una cartera propia de valores, como remedio a las dificultades que introducía el hecho de invertir todo su efectivo en el monte, que por su parte ya no era capaz de absorber el capital que los impositores colocaban en la caja. A lo largo de los años comprendidos entre 1880-1900 el problema se fue agravando y la entidad hubo de adoptar medidas tendentes a limitar las imposiciones, ya que tenía serias dificultades para colocar sus fondos en préstamos del monte; así, en $1888^{39}$ la caja sufrió una importante crisis por exceso de tesorería. La solución adoptada por el Consejo de la misma (compra de un importante paquete de obligaciones hipotecarias de los Ferrocarriles del Norte), lejos de arreglar la situación provocó cierta alarma social y se produjeron retiradas masivas de capital que redu-

${ }^{38}$ En 1875 la entidad madrileña contará con un nuevo Estatuto y un Reglamento de funcionamiento que lo desarrollaba, asimismo la estabilidad económica y política que se inicia en ese año marcarán una nueva etapa de estabilidad. Sobre este aspecto consultar M. Titos (1989), pp. 557-587.

${ }^{39}$ Sobre la crisis y su evolución consultar las Memorias y Cuentas Generales del Monte de Piedad y Caja de Ahorros de Madrid de los años 1885 a 1890. También M. Titos (1989). La alarma creada entre los impositores vino a cuenta de la difusión de que esos valores no iban a ser de fácil realización para la caja, produciéndose una cierto pánico que terminó por extenderse durante el mes de octubre de 1888, devolviendo la entidad en ese mes 24 millones de pesetas a 14.000 impositores. 


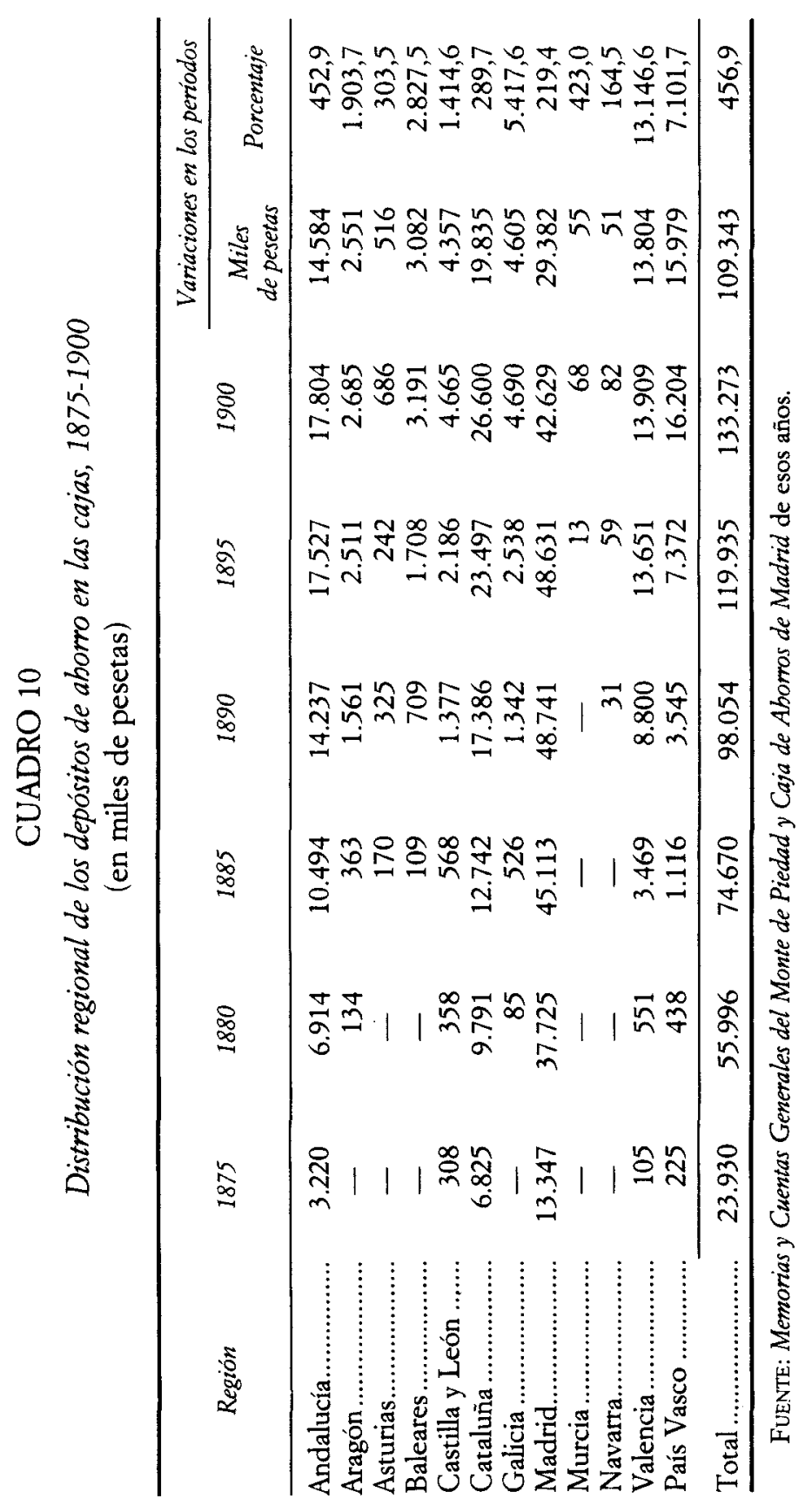


jeron de manera considerable las liquideces acumuladas. M. Titos ${ }^{40}$ señala que esta situación pudo estar relacionada con una operación para reducir la actividad del establecimiento, y en general de todos ellos, al ámbito meramente asistencial. Ello explicaría el estancamiento experimentado durante el período 1890-1895 y la posterior caída entre 1897-1900 en la captación de depósitos; se trataría de una operación de autoajuste de la entidad tendente a redimensionar su capacidad de absorción de imposiciones, renunciando con ello a convertirse en una de las principales instituciones financieras del país si se hubieran adoptado las medidas oportunas para invertir adecuadamente el capital sobrante.

El conjunto de cajas catalanas configura a Cataluña como la segunda región en la captación de depósitos, con una participación muy constante durante todo el conjunto de años señalados. El máximo lo alcanzó en 1875 con el 28,5 por 100 del total de los mismos, para estancarse en torno al 17 por 100 entre $1880-1890$ y en torno al 19 por 100 entre 1895-1900. Como han mostrado J. Nadal y C. Sudriá ${ }^{41}$ las cajas catalanas compensaron con sus actuaciones en el sentido indicado el declive financiero que se experimentó a partir de 1898 , iniciando una expansión geográfica acompañada por el crecimiento de las cuentas individuales de ahorro de una nueva clientela formada por capas de la pequeña burguesía. Después de ellos, el siguiente grupo es el constituido por los establecimientos andaluces, dentro de los cuales destaca la posición del Monte de Piedad y Caja de Ahorros de Sevilla, que por volumen de depósitos será la tercera durante todo el período a que nos referimos. En 1875 la entidad disponía del 12,3 por 100 del total a nivel del Estado, pasando al 10,9 por 100 en 1880 , al 11,7 por 100 en 1885 , para terminar perdiendo el tercer lugar en 1900 con el 7,8 por 100, en beneficio de la Caja de Ahorros y Monte de Piedad de Valencia El crecimiento del bloque regional de Andalucía fue constante entre 1875-1890, estancándose entre 1895-1900. Por último, resta el grupo constituido por Valencia y País Vasco, entre las cuales sobresalen la Caja de Ahorros y Monte de Piedad de Valencia y la de San Sebastián, respectivamente. Al final del período el conjunto de entidades vascas superó en volumen de depósitos a las valencianas, situándose próximo a Andalucía en 1900 , con el 12,1 por 100 del capital impuesto en el ámbito estatal. Por número de establecimientos el conjunto Valencia-Murcia (que constituirá más tarde la Federación Levantina de Cajas

${ }^{40}$ M. Titos (1989), p. 576.

${ }^{41}$ J. Nadal y C. Sudriá (1983), especialmente las pp. 82-96. 


\section{CUADRO 11}

Relaciones entre las magnitudes de la renta nacional, los depósitos de las cajas de aborros y los depósitos de la banca privada

no emisora, 1854-1913

\begin{tabular}{|c|c|c|c|c|c|}
\hline \multirow[b]{2}{*}{ Años } & \multirow[b]{2}{*}{$\begin{array}{l}\text { Renta } \\
\text { Nacional } \\
\text { (millones } \\
\text { de pesetas } \\
\text { comientes) }\end{array}$} & \multicolumn{2}{|c|}{ Cajas de aborros } & \multicolumn{2}{|c|}{ Banca privada } \\
\hline & & $\begin{array}{c}\text { Depósitos } \\
\text { de las cajas } \\
\text { de aborros } \\
\text { (millones } \\
\text { de pesetas } \\
\text { corrientes) }\end{array}$ & $\begin{array}{l}\text { Porcentaje } \\
\text { de los depósitos } \\
\text { respecto a la } \\
\text { Renta Nacional }\end{array}$ & $\begin{array}{l}\text { Depósitos } \\
\text { de aborro } \\
\text { en banca } \\
\text { privada } \\
\text { (millones } \\
\text { de pesetas } \\
\text { corrientes) }\end{array}$ & $\begin{array}{c}\text { Porcentaje } \\
\text { de los depósitos } \\
\text { respecto } \\
\text { a la Renta } \\
\text { Nacional }\end{array}$ \\
\hline $1854 \ldots \ldots \ldots \ldots \ldots$ & 3.825 & 5,3 & 0,13 & 37,0 & 0,96 \\
\hline $1874 \ldots \ldots \ldots \ldots \ldots \ldots$ & 4.497 & 15,6 & 0,34 & 63,0 & 1,40 \\
\hline $1880 \ldots \ldots \ldots \ldots \ldots$ & 5.210 & 55,9 & 1,07 & 215,6 & 4,13 \\
\hline $1882 \ldots \ldots \ldots \ldots \ldots$ & 6.197 & 62,9 & 1,01 & 165,8 & 2,67 \\
\hline $1888 \ldots \ldots \ldots \ldots \ldots$ & 6.708 & 78,2 & 1,16 & 217,4 & 3,24 \\
\hline $1890 \ldots \ldots \ldots \ldots \ldots$ & 6.747 & 97,6 & 1,44 & 193,6 & 2,86 \\
\hline $1894 \ldots \ldots \ldots \ldots \ldots . . . . . . . .$. & 6.825 & 114,7 & 1,68 & 188,1 & 2,75 \\
\hline $1900 \ldots \ldots \ldots \ldots \ldots$ & 10.152 & 131,0 & 1,29 & 402,3 & 3,96 \\
\hline $1913 \ldots \ldots \ldots \ldots \ldots$ & 13.086 & 348,8 & 2,66 & 596,6 & 4,55 \\
\hline
\end{tabular}

Fuente: Las cifras sobre la Renta Nacional tomadas de A. Alcaide (s. f.), vol. II, y para los años 1870 y 1880 de Leandro Prados de la Escosura (1982), estimaciones realizadas a partir de los cálculos de Mulhall. Los datos de las cajas de ahorros proceden de los cuadros anteriores. Las cifras de los depósitos bancarios están tomadas de G. Tortella (1974), pp. 490 y 499, y los datos de los años 1854 y 1874 de P. Martín Aceña (1985), p. 131.

de Ahorros) y Cataluña-Baleares es la agrupación territorial que va en cabeza: 14 en cada uno de los dos subconjuntos al finalizar el siglo, seguidos a distancia por Andalucía con seis.

El valor medio de las cuentas nos puede servir como indicador de la capacidad de ahorro de la clientela de las cajas. Entre 1875-1900 éste fue de 666 pesetas/cuenta, con un máximo en el quinquenio 1885-1889 (702,8 pesetas) y un mínimo entre 1900 y 1904 (598,4 pesetas), mostrando una tendencia al estancamiento entre 1890-1899 y descendiendo en el siguiente quinquenio. Estamos hablando, pues, de cifras modestas que muestran claramente la extracción social y económica, reiteradamente señalada, de los impositores. Estos valores medios cambian considerablemente de un establecimiento a otro; así, las de Madrid, Sevilla, Jerez y Valladolid tuvieron durante prácticamente todo el período señalado cuentas con saldos 
medios superiores a mil pesetas, lo que muestra una mayor penetración entre la pequeña burguesía urbana, mientras que entidades importantes por su volumen de depósitos como las de Barcelona, Valencia, Zaragoza - Sabadell presentaban cuentas con saldos medios que oscilaban entre las 300 y 800 pesetas, lo cual indica una clientela de menor capacidad de ahorro que podía proceder de las capas populares de las ciudades.

Otra valoración del peso de las cajas dentro del marco económico general del país se puede obtener de la comparación con los valores de la Renta Nacional, como se muestra en el cuadro 11. El ritmo de crecimiento de los depósitos de ahorro de las cajas y de la banca fue mucho mayor que el de la renta nacional, siendo más uniforme el de las primeras y con muchas más variaciones el de la segunda debido a la mayor repercusión de las distintas crisis financieras sobre la banca privada. Por último, si comparamos los recursos ajenos de las cajas españolas con la de países del entorno próximo obtenemos el siguiente resultado (cuadro 12):

\section{CUADRO 12}

Comparación de los saldos de aborro en las cajas de España, Italia y Francia, 1840-1900

\begin{tabular}{|c|c|c|c|c|c|c|}
\hline \multirow[b]{2}{*}{$A \bar{n} o s$} & \multicolumn{2}{|c|}{ España } & \multicolumn{2}{|c|}{ Italia } & \multicolumn{2}{|c|}{ Francia } \\
\hline & $\begin{array}{l}\text { Millones } \\
\text { de pesetas }\end{array}$ & $\begin{array}{c}\text { Indice } \\
1875=100\end{array}$ & $\begin{array}{l}\text { Millones } \\
\text { de pesetas }\end{array}$ & $\begin{array}{c}\text { Índice } \\
1875=100\end{array}$ & $\begin{array}{l}\text { Millones } \\
\text { de pesetas }\end{array}$ & $\begin{array}{c}\text { Indice } \\
1875=100\end{array}$ \\
\hline $1840 \ldots \ldots \ldots \ldots$ & 0,7 & 2,9 & 18,9 & 3,6 & - & - \\
\hline $1845 \ldots \ldots \ldots \ldots$ & 2,3 & 9,7 & 38,6 & 7,3 & - & - \\
\hline $1850 \ldots \ldots \ldots \ldots$ & 4,1 & 17,4 & 40,0 & 7,6 & - & - \\
\hline $1855 \ldots \ldots \ldots \ldots$ & 5,9 & 25,1 & 94,3 & 17,9 & - & - \\
\hline $1860 \ldots \ldots \ldots \ldots$ & 10,3 & 43,8 & 157,2 & 29,8 & - & - \\
\hline $1865 \ldots \ldots \ldots \ldots$ & 11,6 & 49,3 & 224,9 & 42,6 & - & - \\
\hline $1870 \ldots \ldots \ldots \ldots$ & 9,3 & 39,5 & 348,1 & 66,0 & $1.425,9$ & 81,4 \\
\hline $1875 \ldots \ldots \ldots \ldots$ & 23,5 & 100,0 & 527,2 & 100,0 & $1.750,0$ & 100,0 \\
\hline $1880 \ldots \ldots \ldots \ldots$ & 56,0 & 238,2 & 686,7 & 130,2 & $1.802,5$ & 102,9 \\
\hline $1885 \ldots \ldots \ldots \ldots$ & 73,0 & 310,6 & $1.033,3$ & 196,0 & $2.365,5$ & 135,1 \\
\hline $1890 \ldots \ldots \ldots \ldots$ & 97,6 & 415,3 & $1.166,3$ & 221,2 & $3.225,1$ & 190,0 \\
\hline $1895 \ldots \ldots \ldots \ldots$ & 118,2 & 502,9 & $1.343,7$ & 254,8 & $4.152,9$ & 237,3 \\
\hline $1900 \ldots \ldots \ldots \ldots$ & 131,1 & 557,8 & $1.504,7$ & 285,4 & $4.274,2$ & 244,2 \\
\hline
\end{tabular}

Fuente: Los datos de Italia están tomados de Leopoldo Viali (1913) y los de Francia de A. Chevauchez (1906). Los de España de los cuadros 2 y 8. 
El cuadro revela, como también se señaló, la modestia de los resultados de las cajas españolas frente a las de Italia o Francia, en consonancia con el distinto nivel de desarrollo de las respectivas economías nacionales. El temprano despliegue del sistema de cajas en Francia (la de París se fundaba en 1818) y la acertada ordenación legislativa ${ }^{42}$ hicieron que su número creciera considerablemente: de 14 entidades existentes en 1830 se pasó a 541 con 904 sucursales en 1881 . La crisis económica de 1847 y el cambio político de 1848 pusieron a prueba el sistema, que se volvió a reorganizar con una nueva serie de leyes ( 1851 y 1853 ) hasta la guerra franco-prusiana. Un Decreto de 17 de septiembre de 1870 salvó la situación producida por la desmesurada petición de reembolsos, estableciendo límites a los mismos e introduciendo la devolución a través de Bonos del Tesoro. En 1881 la intervención del Estado se hizo más directa a partir de la fundación de la Caisse Nationale d'Epargne o Caisse d'Epargne Postale, lo que supuso la creación de más de 7.000 agencias que llegaron hasta los más apartados rincones tanto del país como de las colonias. La misma ley permitía por primera vez que las mujeres pudieran abrir, sin consentimiento previo de sus maridos o tutores legales, cuentas de ahorros o retirar fondos, hecho que se hizo extensivo a los jóvenes a partir de los seis años, con lo cual se abría la puerta al «jeune apprenti ouvrier» y a su actuación como clientes de las cajas. La influencia del modelo francés sobre el sistema español fue un hecho; la propia Caja de Madrid copiaba los reglamentos de funcionamiento de la de París.

\section{La demanda de crédito sobre el sistema cajas-montes de piedad y su respuesta entre 1862-1901}

Es un hecho constatado la escasez de dinero en los mercados formales de crédito durante todo el siglo XIX, conclusión a la que han llegado diversos trabajos como los de G. Tortella ${ }^{43}$ y P. Martín Aceña ${ }^{44}$; y en la misma dirección apuntan los resultados de las encuestas realizadas por los poderes públicos durante la segunda mitad del siglo ${ }^{45}$. El problema de la usura terminó por convertirse en un lugar común que justificó la aparición de

${ }^{42}$ La Ley de 5 de junio de 1835 , la de 31 de marzo de 1837 y la de 22 de junio de 1845 ordenaron con acierto el funcionamiento del sistema. Sobre este aspecto ver B. Antón Ramírez (1876), pp. 156-162.

${ }^{43}$ G. Tortella (1974).

${ }^{44}$ P. Martín Aceña (1985), pp. 121-146.

45 Sobre este asunto consultar A. P. Martinez Soto (1994). 
múltiples estudios proponiendo soluciones de todo tipo con el fin de reducir el peso de los mercados informales tanto en el medio urbano como en el rural, y de incentivar la expansión del consumo reproductivo entre las clases populares ${ }^{46}$. Incluso esta situación ha provocado un intenso debate historiográfico con posturas enfrentadas; por un lado, los que afirman que la escasez de la demanda no favorecía la fundación ni el desarrollo de instituciones crediticias fuertes, y por otro, los que acusan a la escasa oportunidad de ganancias que generaba el panorama económico del pais y a la rigidez de la oferta de crédito de ser los causantes del limitado desarrollo institucional y del predominio de los organismos de carácter particular durante el siglo XIX.

En este contexto actuaron los 14 montes de piedad que funcionaron durante el período estudiado. Este bajo número de establecimientos constituye en sí mismo un indicador sobre las posibilidades reales de los mismos de incidir con efectividad en el mercado de crédito. Sin embargo, algunos de ellos sí tuvieron una intervención destacada sobre las redes de usura existentes en sus ámbitos de actuación; por ejemplo en el caso del Monte de Piedad-Caja de Ahorros de Madrid, que redujo considerablemente la influencia de las casas privadas de empeños de la ciudad ${ }^{47}$. Entre 1874-1884 desaparecieron 150 establecimientos de este tipo, conservándose solamente 95 , de los cuales 68 prestaban sobre prendas y 27 sobre sueldos (préstamos personales), siendo la tasa de interés normalizada del 5 por 100 mensual ${ }^{48}$. En 1884 el volumen de sus operaciones era el siguiente (cuadro 13).

Ese mismo año el Monte de Piedad y Caja de Ahorros de Madrid realizaba 130.516 empeños sobre ropas y alhajas por un valor de 8.762 .656 pesetas y 1.158 préstamos sobre valores por una cantidad de 27.963 .673 pesetas, en total 136.674 operaciones por valor de 36.726 .329 pesetas, todos ellos negociados al 6 por 100. Las operaciones sobre prendas tuvieron un valor medio de 67,1 pesetas y las que se realizaron sobre valores 24.148 . Las primeras, que eran las que realmente utilizaban los diferentes estratos de las clases populares, resultan muy reducidas frente a las que realizaban las casas privadas de empeños, aunque tanto el capital prestado como el

to Sobre el funcionamiento de los mercados informales de crédito y el funcionamiento de la usura en estructuras agrarias atrasadas ver el trabajo de A. Badhuri (1987), pp. 102-121.

17 Así lo atestigua el trabajo del Síndico del Gremio Juan de Dios de Blas (1884), Memoria acerca de lo que son las casas de préstamos sobre prendas, sus productos, gastos y riesgos, $y$ de la influencia que ejercen en la vida social y necesidades privadas, Madrid.

t* Juan de Dios de Blas (1884), pp. 19 a 21. 


\section{CUADRO 13}

La oferta de crédito privado infimo en Madrid, 1884.

Las casas de préstamo sobre prendas

\begin{tabular}{rrrrr}
\hline $\begin{array}{c}\text { Numero de casas } \\
\text { de préstamo } \\
\text { sobre prendas }\end{array}$ & $\begin{array}{c}\text { Operaciones } \\
\text { que venfican } \\
\text { al mes }\end{array}$ & $\begin{array}{c}\text { Operaciones } \\
\text { que realizan } \\
\text { en el año }\end{array}$ & $\begin{array}{c}\text { Capital anual } \\
\text { que prestan } \\
\text { (pesetas) }\end{array}$ & $\begin{array}{c}\text { Valor medio } \\
\text { de la operación } \\
\text { (pesetas) }\end{array}$ \\
\hline 4 & 16.000 & 192.000 & 672.000 & 3,5 \\
12 & 36.000 & 432.000 & 1.728 .000 & 4,0 \\
12 & 24.000 & 288.000 & 1.296 .000 & 4,5 \\
6 & 9.000 & 108.000 & 540.000 & 5,0 \\
6 & 6.000 & 72.000 & 432.000 & 6,0 \\
5 & 4.500 & 54.000 & 378.000 & 7,0 \\
5 & 4.000 & 48.000 & 384.000 & 8,0 \\
4 & 2.800 & 33.600 & 302.000 & 9,0 \\
4 & 2.400 & 28.800 & 288.000 & 10,0 \\
& 1.500 & 18.000 & 216.000 & 12,0 \\
& 1.200 & 14.400 & 180.000 & 15,0 \\
\hline Total & 107.400 & 1.288 .800 & 6.416 .400 & - \\
\hline
\end{tabular}

FUENTE: Juan de Dios de Blas (1884), pp. 10-11.

valor medio de la operación fueron mayores. Con este panorama se puede afirmar que la labor de oferta de crédito del Monte madrileño no era suficiente para atender la demanda de dinero de los peticionarios de extracción humilde, lo cual ayuda a entender que siguieran subsistiendo las casas de empeños y que éstas resultaran todavía a final del siglo un negocio saneado. La mayor parte del capital que prestaba el Monte se dirigía a cubrir las demandas de capital de la mediana y pequeña burguesía urbana, a la cual se destinaba el 76,14 de su inversión en préstamos, con un valor medio considerable (24.148 pesetas). La respuesta a las demandas de capital por parte del binomio montes de piedad-cajas de ahorros se concretó en la siguiente oferta crediticia (cuadro 14).

Resulta interesante resaltar que durante los años 1862-1871 los depósitos de las cajas fueron insuficientes para atender la demanda de capital, teniendo que recurrir los montes de piedad a otras fuentes de financiación que, por lo general, estaban constituidas por sus propios fondos fundacionales y de reserva, lo que suponía poner en peligro la supervivencia 


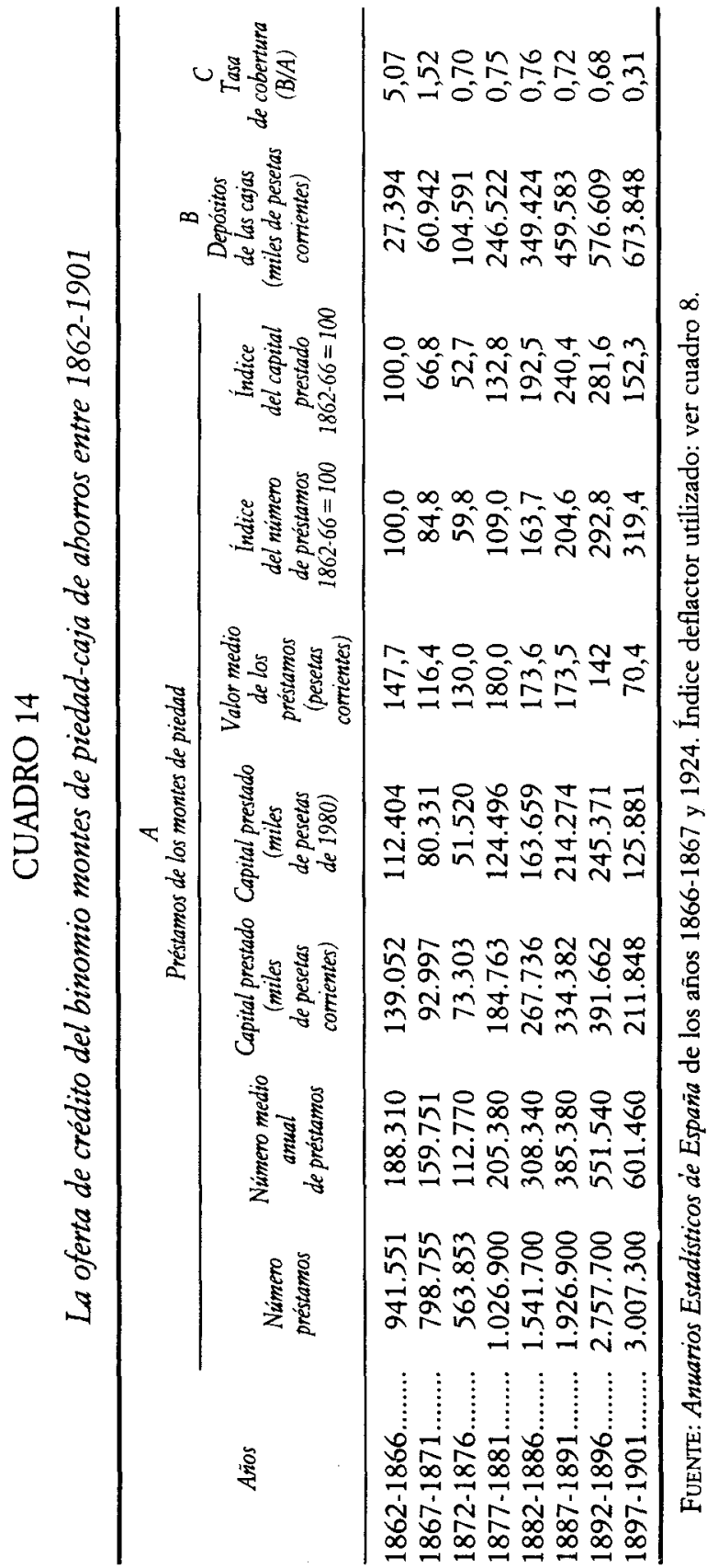


de los mismos. Esta situación comenzó a mejorar hacia 1872-1876, etapa a partir de la cual la demanda de capital para emplear en sus préstamos empieza a ser inferior a la oferta de depósitos de las cajas, viéndose obligadas éstas a canalizar sus excedentes hacia otros tipos de inversión, por lo general valores públicos o préstamos de índole personal que irán sustituyendo a los empeños de ropas y alhajas. El mayor exceso de cobertura por parte de las cajas se produjo en 1897-1901 con una tasa de 0,31, en estos años las grandes oficinas de Madrid, Sevilla, Valencia, etc., iniciaron una política de adquisición de valores públicos ${ }^{49}$ como inversión alternativa que irá absorbiendo la mayor parte de sus recursos ajenos; en el caso de las catalanas se trató de adelantos a pequeños industriales (Barcelona, Mataró, Sabadell, etc.), como también el caso de la entidad de Alcoy.

La dimensión media de los préstamos osciló entre un máximo de 180 pesetas en $1877-1881$ y un mínimo en $1897-1901$ con 70,4 pesetas; por lo tanto seguimos hablando de pequeñas cantidades cuya finalidad mayoritaria era la de atender las necesidades de consumo más perentorias de las familias de extracción social modesta o muy modesta. Aun así, hay que reconocer el peso de los préstamos sobre valores, acciones, etc., que, como hemos tenido ocasión de señalar, superaban de manera muy considerable los valores de los referidos a empeños, y que se dirigían a un sector social más acomodado a través de préstamos en la modalidad personal. Otro hecho que llama la atención es el crecimiento continuado desde 1877-1881 del número de operaciones de este tipo, las cuales llegarán a superar anualmente el medio millón entre 1892-1901, lo que muestra una creciente disposición de las entidades a atender las demandas de capital.

\section{CONCLUSIONES}

La aparición de las cajas de ahorros en el panorama económico del siglo XIX está ligada al desarrollo de las reformas y a la creación de nuevas instituciones, producto de la implantación del liberalismo y del desarrollo del nuevo orden económico. Con este tipo de entidades la burguesía trataba de generar organismos con capacidad de captar el pequeño ahorro proveniente de las clases populares urbanas y ponerlo en circulación dentro

${ }^{49}$ Así lo muestra M. Titos (1989), p. 578, para el caso del Monte de Piedad y Caja de Ahorros de Madrid. 
de los circuitos financieros ordinarios. El concepto de ahorro que acompaña este proceso tiene un fuerte componente moralizador y educativo respecto a los precitados grupos sociales, ya que nacen con la intencionalidad de atender y mejorar las condiciones de vida de las clases más desfavorecidas, basándose para ello en los principios de beneficencia y filantropía que preconiza el nuevo orden social liberal y burgués (malthusianismo).

La mayor parte de las cajas y montes que se fundaron en el período estudiado lo fueron por la iniciativa privada (Sociedades Económicas de Amigos del País, grupos eclesiásticos y corporaciones religiosas, grupos laicos burgueses - comerciantes, industriales, etc.--, organizaciones y asociaciones agrarias...). El Estado sólo se ocupó de «estimular» este tipo de iniciativas, permitiendo su actuación y regulando a posteriori su funcionamiento a través de normativa legal ( $\mathrm{RO}$ de 3 de abril de 1835, RO de 17 de abril de 1839, RD de 29 de junio de 1853, Ley de 29 de junio de 1880); cuando intentó utilizar los fondos de las cajas para incrementar el crédito público llegó a poner en peligro su continuidad debido a la desconfianza que generaba entre los depositantes. Las corporaciones locales realizaron una labor positiva de fundación de institutos, incluso se distanciaron de su gestión y evitaron forzar la colocación de los depósitos de las mismas en créditos preferentes a la hacienda local a largos plazos, dado que allí donde se intentó realizar esta política se produjo la quiebra de la entidad al retirar los depósitos los impositores. La clientela se componía mayoritariamente, como he mostrado con los datos disponibles, de mujeres sin profesión (dedicadas a «sus labores») y niños de los medios urbanos (38,2 por 100 en 1867 , el 45,1 por 100 para el caso de la Caja de Madrid durante el período 1839-1873), los siguientes grupos en importancia son los trabajadores domésticos y los artesanos, el resto de los grupos profesionales no tienen relevancia salvo en caso de las cajas catalanas, en las que obreros industriales, pequeños industriales y comerciantes tienen una mayor presencia. Se puede afirmar que fueron los grupos urbanos más humildes los que utilizaron con carácter preferente los servicios de los establecimientos estudiados. Durante la segunda fase del período estudiado (1868-1904) se produjo la consolidación del sistema de las cajas de ahorros, en parte debido a las disposiciones positivas de la Ley de 1880 que favorecieron su configuración como instituciones de carácter social, superando el estrecho marco de la beneficencia, y las dotaron de autonomía de gestión al desvincularlas funcional y orgánicamente de la obligación de estar ligadas a los montes. Esta nueva configuración favoreció su crecimiento y mayor peso dentro del conjunto del sistema financiero 
español, como se ha podido comprobar a lo largo de este trabajo, debido al incremento de los depósitos y a una mayor preocupación de sus directivos por realizar una gestión más eficaz desde el punto de vista crediticio.

Una de las principales funciones que cumplieron a lo largo del siglo XIX fue contribuir al crecimiento económico y al bienestar social; hemos podido comprobar la correlación existente entre el crecimiento de las principales macromagnitudes económicas y el de los depósitos de ahorro de estas entidades. Las cajas se irán especializando cada vez más y mejor como instituciones de captación de excedentes de renta personal. Desde fechas tempranas, esa labor de atraer y recibir ahorro disperso en cantidades que fueron creciendo de manera continuada y luego dirigirlas hacia inversiones rentables contribuyó al desarrollo y extensión del mercado institucional del dinero y a la formación de capital. La participación en el proceso de desarrollo económico por parte de dichos establecimientos transcurrió tanto por la vía de la inversión como por la promoción del consumo a través de la concesión de préstamos. El sistema de cajas tuvo un importante protagonismo en la difusión del hábito del ahorro. Ello presenta, además, ciertas connotaciones sociopolíticas, ya que a través de dichas entidades se integraran grupos cada vez más numerosos de distintas clases sociales en los circuitos financieros. De hecho llama la atención la importancia relativamente precoz que conocieron dentro del sistema financiero español en las últimas décadas del siglo XIX, a pesar de su desarrollo limitado en comparación con el que obtuvieron en países de nuestro entorno.

\section{BIBLIOGRAFÍA}

Antón Ramírez, Braulio (1876): Montes de Piedad y Cajas de Aborros. Reseña histórica y crítica. Origen, propagación, progresos y actual estado en España y en el extranjero, conveniencia de generalizarlos en España y medios de conseguirlo, Madrid, Imprenta, Estereotipia y Galvanoplastia de Aribau y Compañía.

Bosc, André (1909): Le rol social des Caisses d'Epargne privées en France et Italie, Paris, Arthur Rousseau.

Chastagneret, G. (1966): La Caisse d'Epargne de Sabadell de 1859 à 1914, Memoire pour l'obtention du diplôme d'Etudes Supérieures d'Histoire, inédita.

CheVauxchez, A. (1906): Les caisses d'epargne en France. Histoire et legislation, Paris, Librairie Chevalier et Riviére.

DE BLAS, Juan de Dios (1884): Memoria acerca de lo que son las casas de préstamos sobre prendas, sus productos, sus gastos, riesgos, y de la influencia que ejercen en la vida social y necesidades privadas, respondiendo al cuestionario número 176 del folleto que ba publicado la Comisión nombrada para la mejora y bienestar de la clase obrera, Madrid, Imprenta de Montegrifo y Cía. 
DuET, Daniel (1981): Les caisses d'epargne françaises et leur activité. Tradition or Evolution (1818-1981), 2 vols., Paris, Moissimier Ed.

Forniés CASAlS, Juan Francisco (1991): «Interpretación básica de la historia de las Cajas de Ahorros españolas», en Papeles de Economia Española, núm. 46, pp. 39.51.

GonZÁlez MoReno, José Manuel (1983): Naturaleza y régimen jurídico de las Cajas de Aborros, Madrid.

GonzÁlez Moreno, José Manuel (1989): «Orígenes de la legislación específica de Cajas de Ahorros en el siglo XIX», en I Simposio de Historia de Cajas de Ahorros y Montes de Piedad, Madrid, comunicación inédita.

Horne, H. Oliver (1947): A bistory of saving banks, London, Oxford University Press.

MaLo, Nicolás (1849): «Paralelo entre el Monte de Madrid y la Caja de Ahorros. Últimos quinquenios», en El Amigo del País, t. VII.

MaRTí ACEÑA, Pablo (1985): «Desarrollo y modernización del sistema financiero, 1844-1935», en La modernización económica de España, 1830-1930, Nicolás SÁNCHEZ-Álbornoz (ed.), Madrid, Alianza Editorial.

MaRTinez Soto, Ángel Pascual (1994): Crédito y aborro popular. El crédito agrícola en la región de Murcia, 1850-1935, tesis doctoral microfilmada, Murcia, Servicio de Publicaciones de la Universidad de Murcia

Monte de Piedad y Caja de Ahorros de Madrid (1888): Memoria y Cuenta General de... en el año 1888, Madrid, Imprenta de José Rojas.

- (1881): Memoria y Cuenta General de... en el año 1881, Madrid, Imprenta de José Rojas.

Montero CANERERo, M. (1983): Bases para la investigación del préstamo y la usura en la sociedad del siglo XIX, Madrid, CECA.

NadAl, Jordi, y Sudria, Carles (1983): Historia de la Caja de Pensiones. La "Caixa" dentro del sistema financiero catalán, Barcelona, Ed. Caja de Pensiones para la Vejez y de Ahorros de Cataluña y Baleares.

Pardo Pimentel, Nicolás (1869): Las Cajas de Aborros. Bases y observaciones sobre la de Paris y la de Madrid. Influencia de estos establecimientos de crédito en la suerte de las clases trabajadoras, Madrid, Imprenta de Sordomudos.

PRADOS DE LA EsCosura, Leandro (1988): De Imperio a Nación. Crecimiento y atraso económico en España, 1780-1930, Madrid, Alianza Editorial.

- (1995): Spain's gross domestic product, 1850-1990, Working paper, Madrid, Universidad Carlos III.

QueVEdo y SAN CRISTóbal, Francisco (1835): Memoria sobre el modo de establecer en España Cajas de Ahorros y asociaciones de socorros mutuos. Madrid, Sociedad Económica Matritense.

Revell, Jack (1989): El futuro de las cajas de aborros. Estudio de España y del resto de Europa, Madrid, Fundación FIES de la CECA.

Rodenas Villena, Clementina (1978): Banca $i$ industialització. El cas valencia. 1840-1880, Valencia, Tres i Quatre.

TEDDE DE LORCA, Pedro (1991): «La naturaleza de las Cajas de Ahorros: sus raíces históricas», en Papeles de Economia Española, núm. 46, pp. 2-11. 
Trtos Marínez, Manuel (1978): «Una investigación sistemática sobre la historia de las Cajas de Ahorros españolas», en Boletín de Documentación del Fondo para la Investigación Económica y Social, vol. X, núms. 1-2, enero-junio.

- (1978): «La Caja General de Depósitos, 1852-1874», en Moneda y Crédito, núm. 54, pp. 79-104

- (1989): «La Caja de Madrid en el siglo XIX: cactividad asistencial o financiera?», en Revista de Historia Económica, núm. 3, pp. 557-587.

- (1991): «La respuesta histórica de las Cajas de Ahorros a las demandas de la sociedad española», en Papeles de Economia Española, núm. 46, pp. 12-37.

- (1993): «Fondation et développement des Caisses d'Epargne en Espagne au XIxe. siècle», en La diffusion de l'idée de Caisses d'Epargne au xixe. siècle. L'Histoire des Caisses d'Epargne Européennes, t. 2, Paris, les Editions de l'Epargne, pp. 139-174.

- (1997): «Conjoncture et crise: les Caisses d'Epargne en Espagne (1850-1914)», en L'Histoire des Caisses d'Epargne Européennes, t. 3, Conjoncture et crises, 1850 à 1914, Paris, les Éditions de l'Epargne, pp. 113-131.

TORTElla CaSARES, Grabiel (1970): «La evolución del sistema financiero español de 1856 a 1868», en Ensayos sobre la economía española de mediados del siglo XIX, Madrid, Servicio de Estudios del Banco de España.

- (1973): Los orígenes del capitalismo en España, Madrid, Tecnos.

- (1974): «Una serie de cuentas de ahorro no bancarias (1874-1914)», en La Banca Española en la Restauración, vol. II, Datos para una bistoria económica, Madrid, Servicio de Estudios del Banco de España.

Vellosillo Rodríguez, Faustino (1972): «La instauración de las Cajas de Ahorros en el siglo XXX y la ideología de la época», en Boletín de Documentación para la Investigación Económica y Social, vol. IV, fase 4, octubre-diciembre.

- (1989): «La introducción de las ideas de las cajas de ahorros en España», en I Simposio de Historia de las Cajas de Aborros y Montes de Piedad, Madrid, comunicación inédita.

VIALLI, Leopoldo (1913): Le casse di risparmio, Milano, Casa Editrice dottor Francesco Villardi. 


\section{ANEXO GRÁFICO GRÁFICO I}

Evolución de las imposiciones en las Cajas de Aborro españolas, 1850-1904

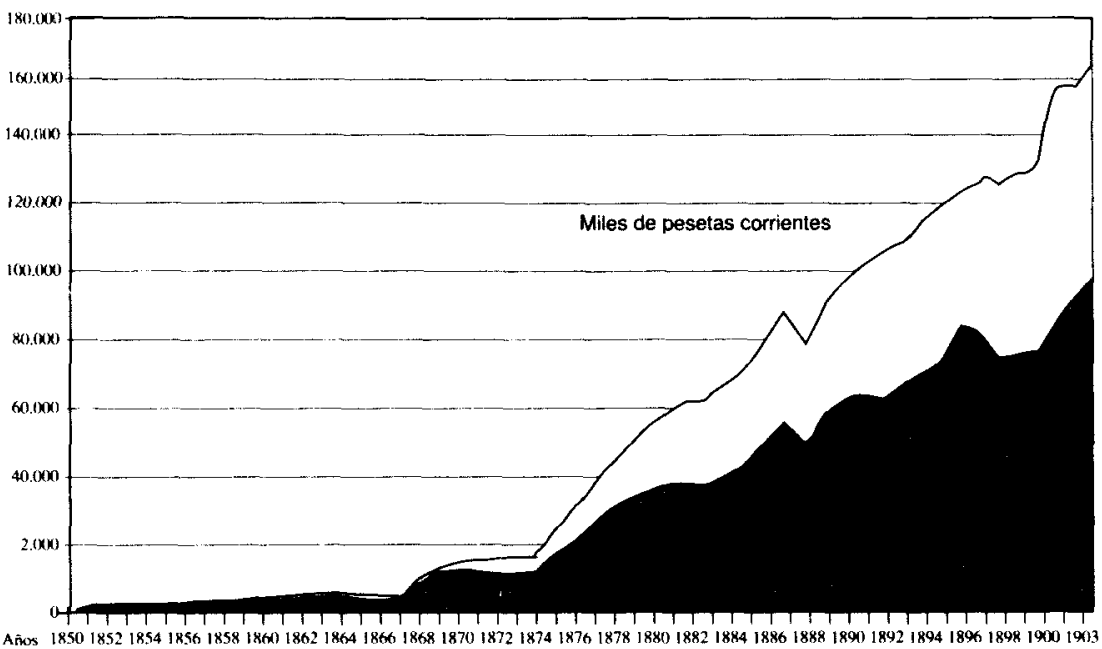

FUENTE: Las indicadas en los cuadros 2 y 8 del texto.

\section{GRÁFICO II}

\section{Relación entre empeños y depósitos de los Montes de Piedad y las Cajas de Ahorro, 1862-1904 (pesetas constantes 1980)}

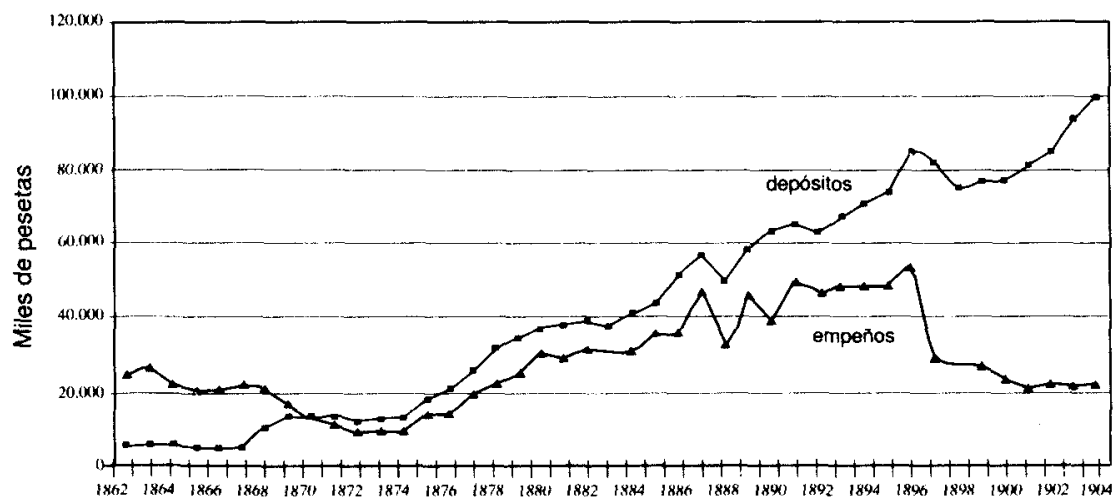

Fuente: Para los depósitos se han tomado las cifras del cuadro 8 del texto y las cifras de la evolución de los empeños se han tomado de las Memorias y Cuentas Generales del Monte de Piedad y Cajas de Ahorro de Madrid para esos años. 


\section{GRÁFICO III}

Evolución de los depósitos de aborro en las principales cajas españolas, 1844-1900

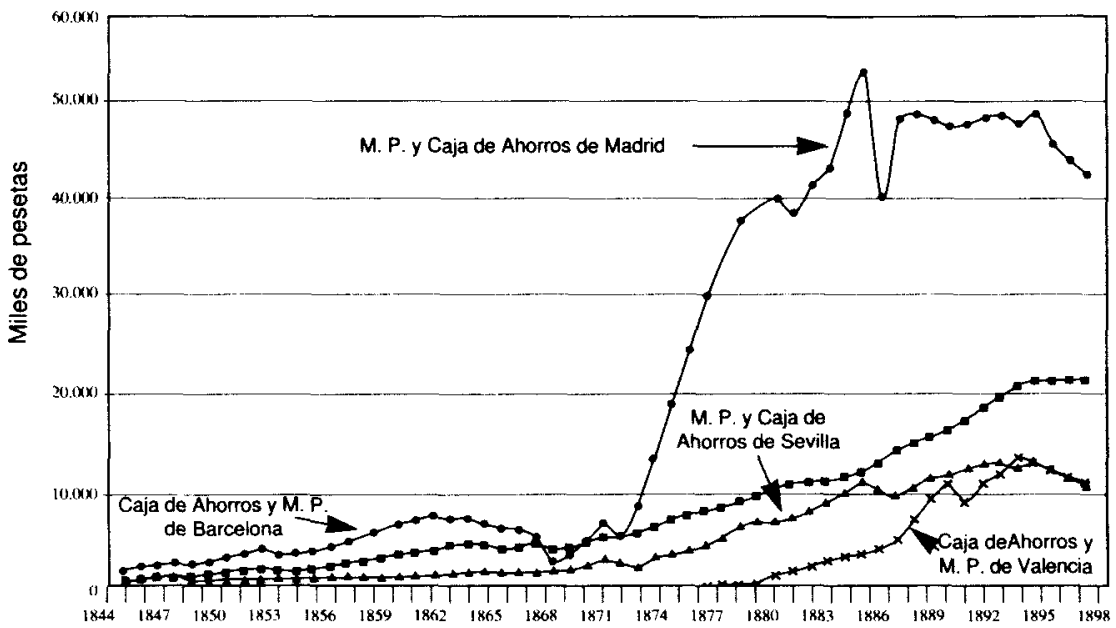

FuENTE: Anuario Estadístico de España, 1866-1867 y Memorias y Cuentas Generales del Monte de Piedad y Cajas de Ahorro de Madrid.

\section{GRÁFICO IV \\ Evolución del capital prestado por el sistema Montes de Piedad-Cajas de Aborro, 1862-1904}

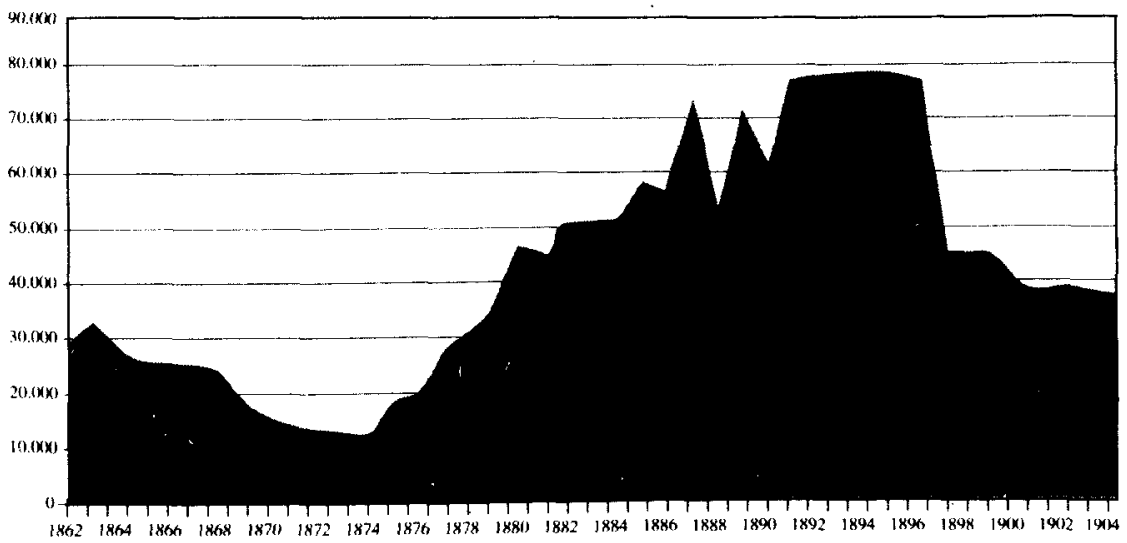

Fuente: Cuadro 14 del texto. 


\section{GRÁFICO V}

Evolución de los depósitos en las Cajas de Aborro y en la Banca española, 1874-1900

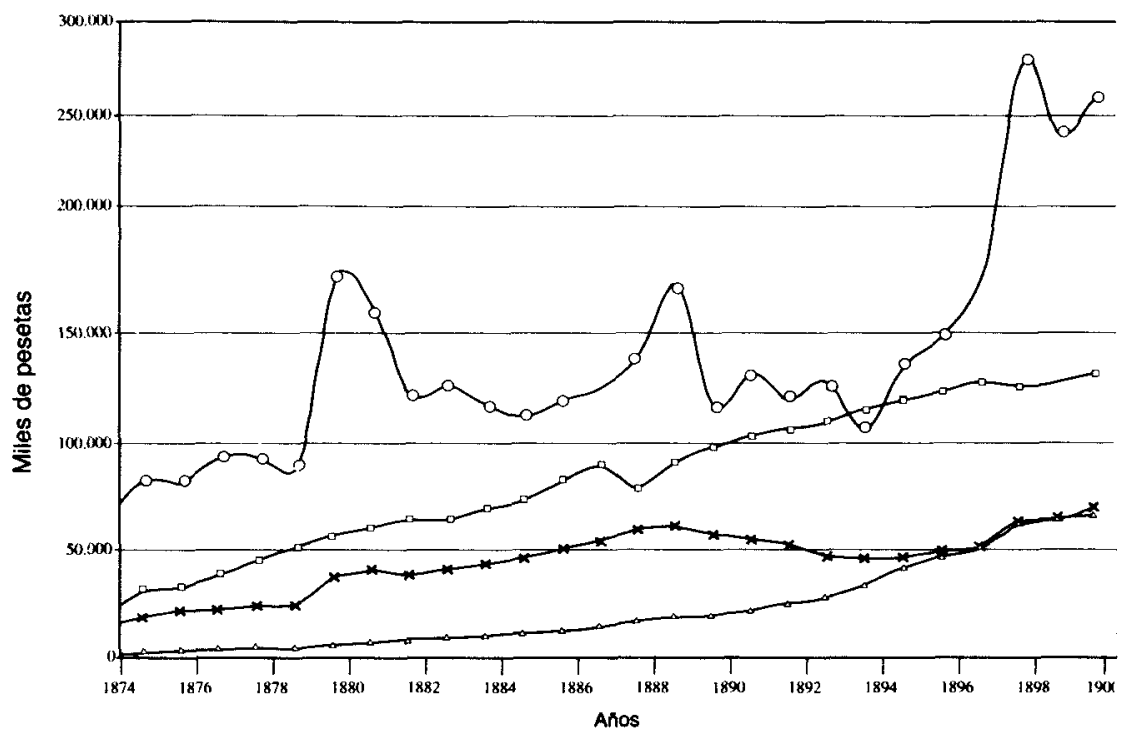

Fuente: Para las Cajas de Ahorro, cuadro 8 del texto; para el resto, Gabriel Tortella (1974), pp. 490 y 499. 